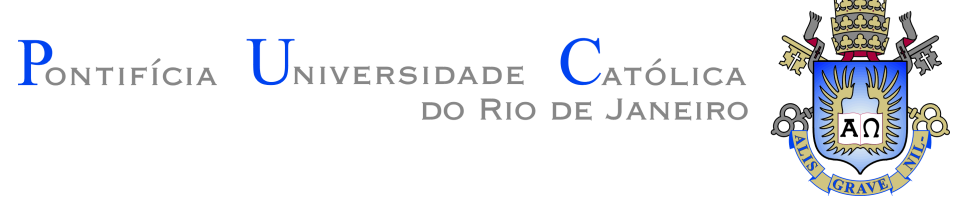

Rodrigo Bianchi Santos

\title{
Otimização Paramétrica de Estruturas Treliçadas Sob a Ação de Cargas Dinâmicas Utilizando o Método do Carregamento Estático Equivalente
}

Dissertação de Mestrado

Dissertação apresentada como requisito parcial para obtenção do grau de Mestre pelo Programa de Pós-graduação em Engenharia Mecânica do Departamento de Engenharia Mecânica do Centro Técnico Científico da PUC-Rio.

Orientador: Prof. Anderson Pereira 

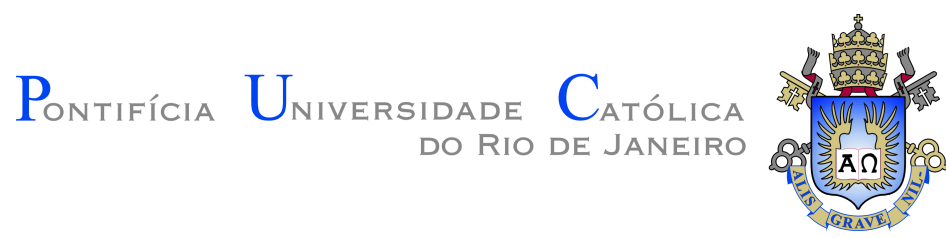

Rodrigo Bianchi Santos

\section{Otimização Paramétrica de Estruturas Trelicadas Sob a Ação de Cargas Dinâmicas Utilizando o Método do Carregamento Estático Equivalente}

Dissertação apresentada como requisito parcial para obtenção do grau de Mestre pelo Programa de Pós-graduação em Engenharia Mecânica do Departamento de Engenharia Mecânica do Centro Técnico Científico da PUC-Rio . Aprovada pela Comissão Examinadora abaixo assinada.

Prof. Anderson Pereira

Orientador

Departamento de Engenharia Mecânica - PUC-Rio

Prof. Ivan Fabio Mota de Menezes

Pontifícia Universidade Católica do Rio de Janeiro - PUC-Rio

Prof. Rodrigo Bird Burgos

Universidade Estatual do Rio de Janeiro - UERJ

Prof. Márcio da Silveira Carvalho

Coordenador Setorial do Centro Técnico Científico - PUC-Rio 
Todos os direitos reservados. É proibida a reprodução total ou parcial do trabalho sem autorização da universidade, do autor e do orientador.

\section{Rodrigo Bianchi Santos}

Bacharel em Engenharia Mecânica pela Pontifícia Universidade Católica do Rio de Janeiro (2015).

Ficha Catalográfica

Santos, Rodrigo Bianchi

Otimização Paramétrica de Estruturas Treliçadas Sob a Ação de Cargas Dinâmicas Utilizando o Método do Carregamento Estático Equivalente / Rodrigo Bianchi Santos; orientador: Anderson Pereira. - 2018.

$64 \mathrm{f}$ : il. color. ; $30 \mathrm{~cm}$

Dissertação (mestrado) - Pontifícia Universidade Católica do Rio de Janeiro, Departamento de Engenharia Mecânica, 2018.

Inclui bibliografia

1. Engenharia Mecânica - Teses. 2. Otimização Paramétrica; 3. Carregamento Estático Equivalente;. 4. Restrições Dinâmicas;. 5. Interface ANSYS-MATLAB. I. Pereira, Anderson. II. Pontifícia Universidade Católica do Rio de Janeiro . Departamento de Engenharia Mecânica. III. Título. 


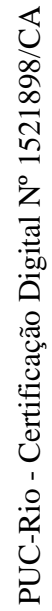

Aos meus pais. 


\section{Agradecimentos}

Primeiramente eu gostaria de agradecer ao Prof. Anderson Pereira, pela sugestão de tema e orientação no mestrado. Sua constante ajuda, ensinamentos e motivações ao longo de todo o processo foram de fundamental importância, sem os quais a conclusão deste trabalho não seria possível.

Também agradeço aos professores Hans Weber, pelo convívio e lições na fase inicial do mestrado e Ivan Menezes, pela ajuda em um momento crítico, me apresentar ao professor Anderson e participação na banca.

Ao Prof. Rodrigo Bird Burgos, pela participação da banca e interesse pelo tema.

À minha mãe, por sempre desejar e fazer seu melhor para mim, nunca desistir e me apoiar em cada segundo, durante toda a minha vida. Eu te amo incondicionalmente, você é o maior exemplo que eu tenho.

Muitas foram as pessoas que acompanharam minha trajetória nos últimos anos, sou grato pela amizade e compreensão de todos que, perto ou distante, fizeram parte deste caminho. Louise Pinho, João Virgolino, André Xavier, Rustam Mesquita, Eduardo Cota, Thiago Almeida, Marisa Bazzi e Gabriel Barsi, companheiros de mestrado, por toda a ajuda e amizade nestes difíceis anos. Marcelo, José, Bruno, Matheus, Juliana, Felipe, Igor, Antonio e Pedro, amigos que a PUC me proporcionou, igualmente importantes na minha vida, obrigado.

À PUC-Rio, pela oportunidade de continuar na instituição no mestrado e sempre incentivar o estudo e pesquisa.

Ao pessoal do Departamento de Engenharia Mecânica, pelo bom convívio.

Ao CNPq, pelo auxílio financeiro. 


\section{Resumo}

Santos, Rodrigo Bianchi; Pereira, Anderson. Otimização Paramétrica de Estruturas Treliçadas Sob a Ação de Cargas Dinâmicas Utilizando o Método do Carregamento Estático Equivalente. Rio de Janeiro, 2018. 64p. Dissertação de Mestrado - Departamento de Engenharia Mecânica, Pontifícia Universidade Católica do Rio de Janeiro .

Otimização estrutural sujeita a carregamentos dinâmicos é um problema desafiador em vários aspectos, a começar pelo grande número de restrições que devem ser atendidas em todos os instantes de tempo. Além disso, o custo computacional para avaliar os gradientes destas restrições é bastante elevado e requer um grande espaço de armazenamento. Na literatura, alguns métodos reduzem o número de restrições avaliando em instantes de tempo selecionados, como o pior caso por exemplo, ou ainda constroem um funcional equivalente, integrando as restrições violadas ao longo do tempo, assim eliminando essa dependência. Nesta dissertação, o método do Carregamento Estático Equivalente (ESL) é utilizado, no qual o problema dinâmico original é transformado em uma sequência de subproblemas de otimização linear estática com múltiplos casos de carga. Um atrativo deste método é a possibilidade da solução de problemas não lineares, evitando o alto custo devido às repetidas análises estruturais e cálculos das restrições. Problemas clássicos de treliças planas submetidas a carregamentos dinâmicos são resolvidos utilizando o método ESL. A função a ser minimizada é a massa da treliça, que está sob restrições de tensão e deslocamento, onde as variáveis de projeto são as áreas da seção transversal dos membros. Além disso, uma interface utilizando ANSYS $^{\circledR}$ e MATLAB $^{\circledR}$ é desenvolvida para uma abordagem modular, na qual a análise via elementos finitos e a otimização possam ser realizadas separadamente. Este processo viabiliza a otimização de estruturas que apresentam comportamentos não lineares a partir da utilização de diversos softwares comerciais disponíveis no mercado.

\section{Palavras-chave}

Otimização Paramétrica; Carregamento Estático Equivalente; Restrições Dinâmicas; Interface ANSYS-MATLAB . 


\section{Abstract}

Santos, Rodrigo Bianchi; Pereira, Anderson (Advisor). Parametric Optimization of Truss Structures Under Dynamic Loading Using the Equivalent Static Load Method. Rio de Janeiro, 2018. 64p. Dissertação de Mestrado - Departamento de Engenharia Mecânica, Pontifícia Universidade Católica do Rio de Janeiro .

Structural optimization subject to dynamic loading is a challenging problem in many aspects, starting with the large number of constraints that must be respected at all instants of time. Furthermore, the computational cost to evaluate the gradients of these constraints is significantly high and requires a large storage space. In the literature, some methods reduce the number of constraints evaluating at selected instants of time, such as the worst case. Alternatively, a single equivalent functional is constructed to eliminate the time dependence by integrating the violated constraints over time. In this work, the Equivalent Static Load (ESL) method is used, in which the original dynamic problem is reduced into a number of static linear optimization problems with multiple load cases. An attractive feature of this method is the possibility of solving non-linear problems, avoiding the high cost due to repeated structural analyzes and constraint calculations. Classical problems of plane trusses subjected to dynamic loads are solved using the ESL method. The function to be minimized is the truss mass, which is subjected to stress and displacement constraints, where the design variables are the cross-sectional areas of the members. In addition, an interface using ANSYS $^{\circledR}$ and MATLAB ${ }^{\circledR}$ was developed for a modular approach, in which finite element analysis and optimization can be performed separately. This process makes possible the optimization of structures that present non-linear behavior from the use of most structural analysis software packages available on the market.

\section{Keywords}

Parametric Optimization; Equivalent Static Load; Dynamic Constraints; ANSYS-MATLAB Interface. 


\section{Sumário}

1 Introdução $\quad 13$

$\begin{array}{lll}1.1 & \text { Motivação } & 14\end{array}$

$\begin{array}{ll}1.2 \text { Revisão Bibliográfica } & 16\end{array}$

1.2.1 Otimização com Restrições Dinâmicas 16

1.2.2 Carregamentos Estáticos Equivalentes 18

$\begin{array}{lll}1.3 \text { Objetivos } & 19\end{array}$

1.4 Organização da Dissertação 19

2 Desenvolvimento Teórico $\quad 20$

2.1 Revisão de Elementos Finitos 20

2.2 Integração no Tempo 24

2.3 Verificação da Análise Dinâmica 26

3 Análise de Sensibilidade $\quad 29$

3.1 Diferenças Finitas 29

3.2 Métodos Analíticos para Análise de Sensibilidade 31

3.2.1 Método de Diferenciação Direta 31

3.2.2 Método Adjunto ou Método do Espaço de Estado 32

3.2.3 Método de Newmark 33

3.2.4 Verificação do Método Direto 35

4 Otimização Estrutural e o Método do Carregamento Estático Equivalente 37

4.1 Formulação do Problema 37

4.1.1 Abordagem Tradicional para Otimização Estrutural Dinâmica 38

4.2 Geração de Carregamentos Estáticos Equivalentes 38

4.3 Otimização Sequencial via ESL 41

4.4 Exemplos Numéricos $\quad 42$

4.4.1 Treliça de 5 Barras $\quad 43$

4.4.2 Treliça de 10 Barras $\quad 47$

4.4.3 Treliça de 20 Barras 52

5 Conclusões $\quad 56$

5.1 Trabalhos Futuros $\quad 57$

$\begin{array}{lll}6 & \text { Referências Bibliográficas } & 58\end{array}$

A Rotina de Análise em Elementos Finitos - Ansys 62 


\section{Lista de figuras}

Figura 1.1 Treliça submetida a um carregamento dinâmico concentrado, na configuração inicial (à esquerda) e otimizada (à direita) 15

Figura 1.2 chute inicial com o vetor de variáveis iniciais igual ao limite inferior. Restrições de tensão violadas.

Figura 1.3 Solução da treliça otimizada. Restrições em todos os membros atendidas.

Figura 1.4 O maior valor dentre as restrições violadas é selecionado como pior caso.

Figura 2.1 Elemento linear de 2 nós; elemento plano de 3 nós; elemento tridimensional de 8 nós.

Figura 2.2 Elemento de barra escrito em um sistema de referências local $\{\mathbf{u}, \mathbf{v}\}$ com coordenadas projetadas em um outro sistema $\{\mathbf{x}, \mathbf{y}\}$.

Figura 2.3 Aceleração média constante (à esquerda) e linear (à direita) pelo método de Newmark.

Figura 2.4 Processo de solução da análise dinâmica via método dos elementos finitos e método de Newmark.

$\begin{array}{lll}\text { Figura 2.5 Treliça de } 3 \text { elementos. } & 27\end{array}$

Figura 2.6 Carregamento linear por partes $P(t) . \quad 27$

Figura 2.7 Resposta do deslocamento horizontal do nó $2 . \quad 28$

$\begin{array}{lll}\text { Figura 2.8 Tensão axial no elemento } 1 . & 28\end{array}$

Figura 3.1 Aproximações por diferenças finitas: diferença à frente (Eq. (3-1)), para trás (Eq. (3-2)) e central (Eq. (3-3)).

Figura 3.2 Derivada do deslocamento horizontal do nó 1 com respeito à área do elemento 1 ao longo do tempo.

Figura 3.3 Derivada da tensão no elemento 1 com respeito à área do elemento 1 ao longo do tempo.

Figura 4.1 Transformação de carregamentos dinâmicos em equivalentes estáticos para vários casos de carga.

Figura 4.2 Caso de carga $s^{k}$ equivalente ao tempo $t$

Figura 4.3 Fluxograma do processo de otimização com a aplicação dos carregamentos estáticos equivalentes.

Figura 4.4 Treliça de 5 barras.

Figura 4.5 Carregamento $\mathrm{P}(\mathrm{t})$.

Figura 4.6 Convergência da função objetivo segundo otimização tradicional, em preto, e utilizando o método ESL, colorido, para a treliça de 5 barras - caso 1 .

Figura 4.7 Ampliação da convergência nos últimos ciclos do método ESL para a treliça de 5 barras - caso 1.

Figura 4.8 Treliça de 10 barras. 
Figura 4.9 Treliça de 10 barras, caso 1. (a) Tensões admissíveis em preto sendo respeitadas durante todo o intervalo de simulação; (b) Deslocamentos verticais não estão sujeitos a restrições.

Figura 4.10 Treliça de 10 barras, caso 3. (a) Tensões respeitam as restrições estabelecidas; (b) Deslocamentos também atendem os limites admissíveis de deslocamento, em preto, em toda a simulação.

Figura 4.11 Treliça de 10 barras, caso 1. Convergência da função objetivo do longo de cada ciclo do método ESL.

Figura 4.12 Treliça de 10 barras, caso 3. Convergência da função objetivo do longo de cada ciclo do método ESL.

Figura 4.13 Treliça de 20 barras.

Figura 4.14 Convergência da função objetivo ao longo de cada ciclo do método ESL utilizando a integração Ansys - Matlab para a treliça de 20 barras.

Figura 4.15 Configuração inicial e otimizada pelo método ESL Treliça de 20 barras. 


\section{Lista de tabelas}

Tabela 4.1 Comparação da função objetivo para a treliça de 5 barras. 45

Tabela 4.2 Número total de iterações em cada método e número de otimizações sequencais estáticas realizadas no método ESL.

Tabela 4.3 Solução ótima ao final de cada iteração do método ESL - Caso 1.

Tabela 4.4 Solução ótima do caso 2 - Comparação entre a referência [34], o método ESL e aborgadem tradicional de otimização com carregamentos dinâmicos.

Tabela 4.5 Restrições envolvidas nos casos 1, 2 e 3 para a treliça de 10 barras.

Tabela 4.6 Função objetivo - Treliça de 10 barras.

Tabela 4.7 Iterações e número de ciclos do método ESL - 10 barras. 51

Tabela 4.8 Convergência das variáveis de projeto ao longo das otimizações sequenciais no método ESL para o caso 1.

Tabela 4.9 Convergência das variáveis de projeto ao longo das otimizações sequenciais no método ESL para o caso 3.

Tabela 4.10 Função objetivo, iterações e número de ciclos do método ESL para a treliça de 20 barras. 
Devemos usar o tempo sabiamente e sempre nos darmos conta de que o tempo é sempre oportuno para fazer o certo.

Nelson Mandela. 


\section{1 \\ Introdução}

Uma das maiores motivações para a pesquisa em campos de engenharia consiste na busca por soluções inteligentes em que o uso de recursos e investimentos controlados são prioridades. Embora pouca atenção tenha sido dada nos séculos passados, onde se deu o berço da engenharia, na atualidade essas prioridades talvez constituam o alicerce no qual a engenharia se baseia e sirva de inspiração para a busca por soluções cada vez mais inovativas para as demandas da sociedade atual.

Em meio a diversas áreas de pesquisa, otimização se destaca como uma das áreas mais importantes no que se diz respeito a obtenção de novas soluções para problemas de engenharia. O uso de otimização tem se mostrado uma ferramenta fundamental no projeto de componentes e estruturas utilizadas em engenharia. Existem diversas possibilidades de aplicação de técnicas de otimização, sendo possível citar as áreas de construção civil, projetos de engenharia aeroespacial e automobilística, turbinas para geração de energia eólica e indústria do petróleo. Novos modelos gerados com ajuda de rotinas automatizadas viabilizam a modelagem de estruturas, peças e componentes que resultam, em geral, em redução de peso ou custo, ao mesmo tempo atendendo às especificações exigidas pelos projetos.

Com o advento da computação, o período entre a década de 50 e 60 marcou o início da otimização estrutural moderna [1], onde máquinas mais poderosas permitiram a manipulação de um volume de dados muito maior. O emprego do método dos elementos finitos se mostrou de fundamental importância para a análise e solução de sistemas estruturais na engenharia, estabelecendo-se no auxílio de pré-processamento em problemas de otimização estrutural. Antes, para se obter a resposta de um sistema estrutural com forçamento estático era necessário o emprego de algum método analítico, por exemplo apoximação por meio de séries infinitas. Métodos numéricos, quando aplicados, eram feitos somente nos últimos passos da solução [2]. 


\section{1 \\ Motivação}

Em linhas gerais, o processo de otimização consiste em obter, a partir de um modelo inicial, o conjunto de parâmetros que minimize (ou maximize) uma ou mais funções que representem o desempenho do modelo em questão. Para completar a formulação do problema de otimização, é necessário que o modelo esteja submetido a certas restrições, que podem ser de distintas origens. Os parâmetros a se obter são chamados variáveis de projeto do problema de otimização, enquanto que as funções de desempenho desejadas são comumente chamadas de função objetivo.

A contar do início da era moderna de otimização estrutural, somente na década de 70, a publicação de Fox \& Kapoor [3] foi pioneira em apresentar compreensivelmente uma forma de se abordar problemas de otimização com restrições dependentes do tempo. Contudo, mesmo na atualidade problemas de otimização estrutural dinâmica continuam a ser desafiadores, devido ao grande tempo gasto na simulação com análise e sensibilidade em problemas de larga escala.

Quando lidamos com problemas reais, raramente as cargas são aplicadas estaticamente na estrutura ou têm natureza puramente estática. Logo, o estudo de problemas estruturais levando em conta efeitos dinâmicos na análise e modelagem tem uma importância grande para se chegar a resultados mais condizentes com os fenômenos observados na realidade. Nestes tipos de problema, os carregamentos aplicados à estutura normalmente variam no tempo, diferentemente de estruturas estáticas, e devem ser analisados e resolvidos com técnicas de abordagem diferentes destas.

Quando se trata de estruturas submetidas a carregamentos que variam ao longo do tempo, as restrições devem ser atendidas em todos os instantes de tempo. Na prática, um número de instantes de tempo é selecionado e o número original de restrições é multiplicado por essa quantidade de amostras de tempo. Dessa forma, o número total de restrições em um problema de otimização com dependência temporal é aumentada consideravalmente.

As Figuras (1.2) e (1.3) exibem a resposta estrutural da tensão axial em cada um dos 10 elementos de uma treliça (Figura 1.1) sujeita a um carregamento dinâmico. Sob a estrutura são consideradas restrições nas quais a tensão axial (tração e compressão) em cada elemento deve ser menor em módulo que $250 M P a$. Na primeira figura, os valores das áreas de cada membro são iguais ao valor mínimo que cada barra pode assumir no problema de otimização. Esta configuração naturalmente seria a solução ótima em um problema sem restrições, mas percebe-se que em vários elementos as restrições são violadas 
em praticamente todo o tempo de análise. Já a segunda imagem apresenta a resposta de tensão para a solução obtida após o processo de otimização. Muitos elementos tiveram suas áreas alteradas até uma configuração na qual as tensões permitidas foram atendidas.
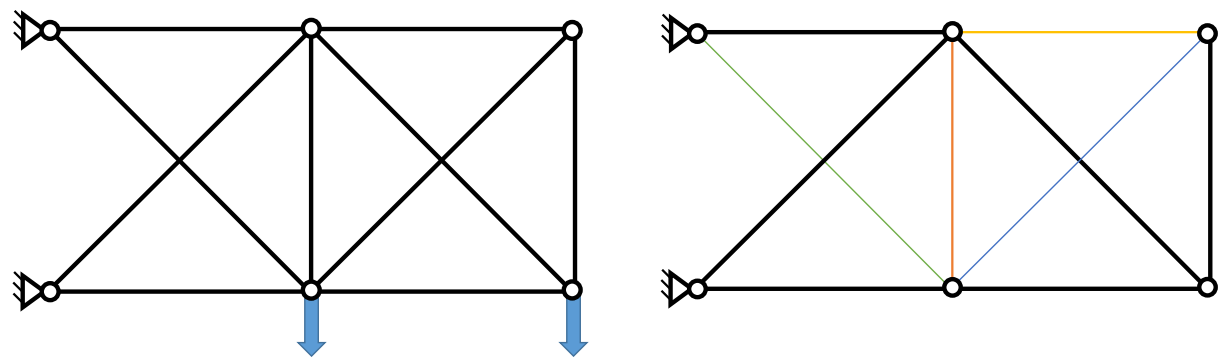

Figura 1.1: Treliça submetida a um carregamento dinâmico concentrado, na configuração inicial (à esquerda) e otimizada (à direita)

Em problemas de larga escala, é fácil de se entender que o número de restrições a se lidar pode ser extremamente grande, sendo assim em muitos casos é um desafio obter a solução ótima num problema de otimização. Outro fator responsável é a dificuldade em lidar com a análise de sensibilidade, sendo estas as equações que descrevem como a função objetivo e as restrições variam com respeito às variáveis de projeto.

A fim de se eliminar a dependência do tempo inerente às restrições e problemas de otimização estrutural dinâmica, diversos métodos foram desenvolvidos de modo a tornar o problema original não relacionado com a dependência temporal. Neste trabalho, o método do carregamento estático equivalente [4] é usado para tratar restrições dinâmicas.

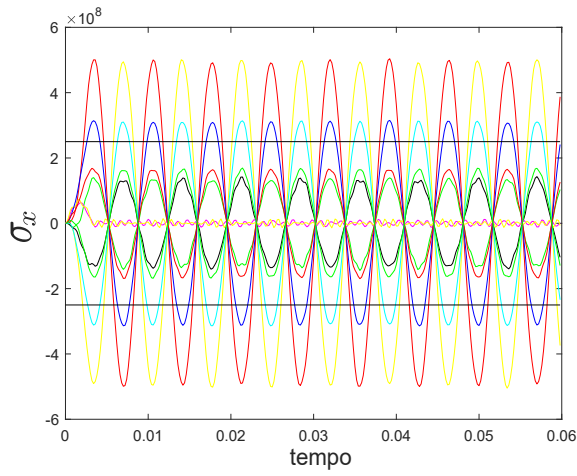

Figura 1.2: chute inicial com o vetor de variáveis iniciais igual ao limite inferior. Restrições de tensão violadas.

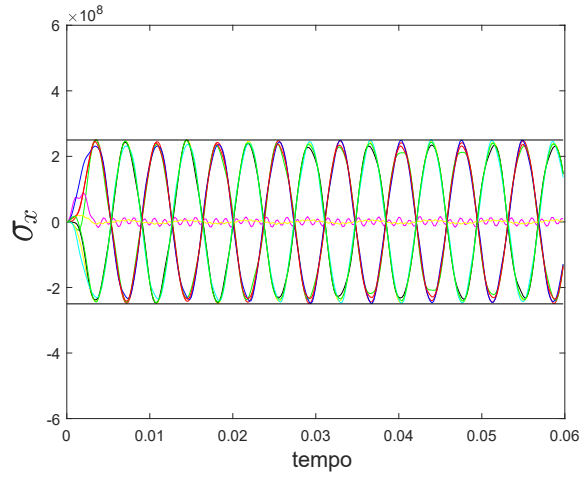

Figura 1.3: Solução da treliça otimizada. Restrições em todos os membros atendidas. 


\section{2 \\ Revisão Bibliográfica}

\subsection{1}

\section{Otimização com Restrições Dinâmicas}

Embora os primeiros estudos envolvendo a idéia de otimização estrutural datem de épocas próximas ao começo do século XX, como em Michell [5], e estudos em projeto de estruturas sob critério de falha com a idéia de mínimo consumo de material (Heyman [6] em 1951), o processo automatizado de otimização como utilizado na atualidade se deu a partir da década de 60, com o trabalho de Schmit [7], onde pela primeira vez a aplicação de técnicas de programação matemática juntamente à analise em elementos finitos para solucionar problemas não lineares de otimização de estruturas elásticas foi realizada. Durante essa década, a maioria dos estudos na área de otimização estrutural foram endereçados à otimização de dimensionamento de estruturas de treliça, vigas e pórticos [8].

A década de 70 presenciou importantes avanços em técnicas aplicadas em otimização estrutural. Fox \& Kapoor [3] apresentaram o primeiro trabalho envolvendo otimização estrutural sujeita a restrições dinâmicas. Além disso, técnicas de critério ótimo foram desenvolvidas e possibilitaram a resolução de problemas com grande quantidade de variáveis de projeto, valor ainda limitado até a década anterior. Em Schmit \& Farshi [9] são apresentadas técnicas de aproximação, como o uso de variáveis e respostas intermediárias e descarte de restrições, que viabilizaram a redução de análises em elementos finitos e cálculo de sensibilidades drasticamente, aumentando muito a eficiência do processo automatizado de otimização. Barthelemy \& Haftka [10] apresentam uma revisão vasta sobre essas técnicas.

A grande maioria dos problemas sujeitos a restrições dinâmicas demandam de muito esforço computacional, principalmente com a computação de derivadas. Em Kang et al. [11] é apresentado um panorama geral sobre essa clase de problemas. O problema estrutural com restrições dinâmicas é discutido e dividido em partes, que são o tratamento das restrições dinâmicas, a análise de sensibilidade e métodos de aproximação para a resposta dinâmica. São apresentados métodos clássicos utilizados para a sua implementação na otimização.

Um típico problema de otimização sujeito a restrições dinâmicas pode ser definido como: 


$$
\begin{array}{ll}
\text { obter } & \mathbf{b} \\
\text { que minimize } & f(\mathbf{b}) \\
\text { sujeito a } & g_{i}(\mathbf{b}, t) \leq 0, i=1, \ldots, m \\
& \mathbf{b}_{l} \leq \mathbf{b} \leq \mathbf{b}_{u} \\
\text { com } & \mathbf{M} \ddot{\mathbf{u}}(t)+\mathbf{C} \dot{\mathbf{u}}(t)+\mathbf{K u}(t)=\mathbf{F}(t)
\end{array}
$$

onde $\mathbf{b}$ é o conjunto de variáveis de projeto, $f$ é a função objetivo, $g_{i}$ é cada restrição de desigualdade a ser atendida, m o número total de restrições de desigualdade, $\mathbf{b}_{l}$ e $\mathbf{b}_{u}$ os limites superior e inferior para as variáveis de projeto. Por fim, a última equação na formulação rege o comportamento dinâmico do sistema, com $\mathbf{M}, \mathbf{C}, \mathbf{K}$ sendo as matrizes de massa, amortecimento e rigidez, $\mathbf{F}$ as forças aplicadas e $\ddot{\mathbf{u}}, \dot{\mathbf{u}}, \mathbf{u}$ as acelerações, velocidades e deslocamentos do sistema.

Na formulação (1-1), as $m$ restrições devem ser atendidas em todos os instantes de tempo. Para lidar com o grande volume restrições, métodos como o funcional equivalente eliminam a dependência do tempo por meio da integração do vetor de restrições no tempo [12]:

$$
\int_{0}^{T}<g_{i}(\mathbf{b}, t)>d t \leq 0
$$

onde a restrição $g_{i}(\mathbf{b}, t)$ só é contabilizada na integral caso seja uma restrição violada. Já na técnica do pior caso, dentre todos os instantes de tempo é selecionada o maior valor da resposta dinâmica que é violada e apenas a restrição associada à ela é usada na otimização. A Figura (1.4) demonstra o procedimento utilizado no método. Como o instante onde a máxima violação ocorre pode variar ao longo da otimização, este processo é bastante lento e apresenta problemas de convergência.

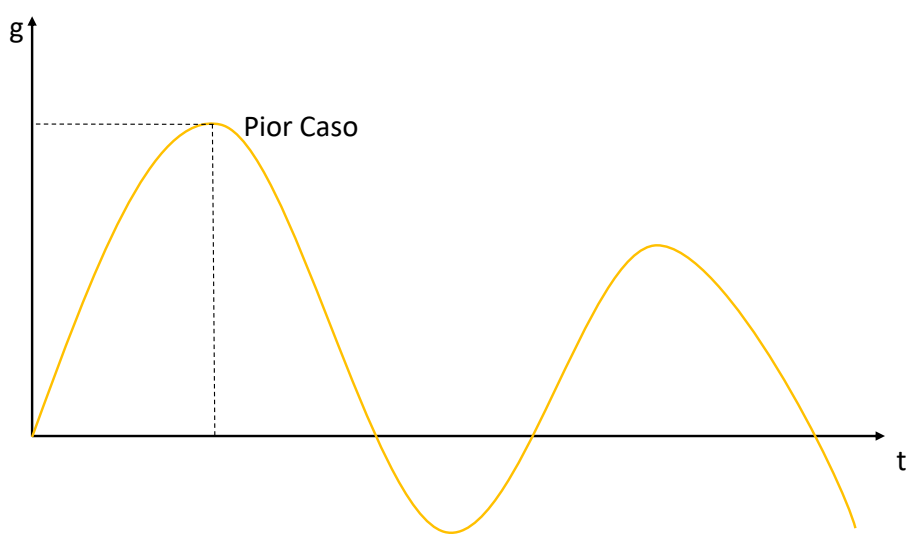

Figura 1.4: O maior valor dentre as restrições violadas é selecionado como pior caso. 


\section{2 .2}

\section{Carregamentos Estáticos Equivalentes}

Tendo em vista a dificuldade presente em muitos problemas de engenharia que contém cargas dinâmicas, diversos estudos foram conduzidos a fim de obter métodos de aproximação práticos e eficientes para a otimização sujeita a carregamentos dinâmicos. A prática corrente em projetos é se transformar os carregamentos dinâmicos em carregamentos estáticos equivalentes. O vento, por exemplo, é dependente do tempo e é considerado na análise como um carregamento estático.

O principal problema de todos esses métodos estudados, apesar de fornecerem bons resultados, é a perda de generalidade, uma vez que os fatores dinâmicos e a escolha dos carregamentos estáticos são puramente de natureza experimental e baseada na experiência do projetista [13].

Na segunda metade da década de 90, Choi \& Park [14] introduziram um método de aproximação chamado método de carregamentos estáticos equivalentes (Equivalent Static Loads, abreviado por ESL), onde o carregamento dinâmico original também é substituído por carregamentos estáticos. Contudo, neste método, os novos carregamentos devem obrigatoriamente gerar o mesmo campo de resposta que o carregamento dinâmico para toda a análise dinâmica. Assim sendo, uma série de otimizações estáticas são conduzidas até que a convergência seja alcançada.

Em Choi \& Park [14] é proposta a transformação de carregamentos dinâmicos em estáticos equivalentes na análise transiente via análise modal. Dois tipos de carregamentos equivalentes, um exato e um aproximado, são deduzidos no artigo e resultados envolvendo estruturas de treliça, viga e pórticos são apresentados.

Kang et al. [13] apresenta problemas de otimização linear estrutural dinâmica utilizando o ESL. Estruturas de viga e treliça com restrições de deslocamento, tensão e frequência são resolvidas. Em Choe et al. [15] O método é utilizado em um problema de otimzação de forma. Contudo, os carregamentos equivalentes são calculados somente em intervalos críticos e não existe um consenso quanto aos pontos de aplicação dos carregamentos. Além disso, diferentes configurações geram diferentes soluções.

Em Choi et al. [16], é proposto um método de otimização no qual o ESL é calculado em todos os intervalos de tempo e aplicados em todos os pontos da estrutura, a fim de estabelecer a generalidade e sistemática ausente em [13]. Em 2003, Park \& Kang [17] publicaram uma nota técnica de modo a validar que a otimização estrutural pelo método ESL e a otimização estrutural dinâmica apresentam a mesma solução, provando que as condições de KKT [29] são 
atendidas. Choi et al. [18] apresenta uma forma de cálculo dos carregamentos estáticos equivalentes baseado em tensões.

Em Shin et al. [19] e Kim \& Park [20], uma nova formulação é proposta para otimização estrutural dinâmica não linear utilizando o ESL. Para se obter numericamente a resposta da tensão são apresentadas equações para correção nos pontos de integração dos elementos. Problemas clássicos envolvendo otimização paramétrica e de forma são resolvidos para a validação do método ESL.

As pesquisas mais recentes envolvem o estudo de problemas de otimização topológica sujeitos a carregamentos dinâmicos, vistos em Jang et al. [21] e aspectos não lineares são introduzidos em Lee \& Park [22].

\section{3}

\section{Objetivos}

Esta dissertação tem como objetivo a implementação do método ESL como uma alternativa eficiente para resolver problemas de otimização estrutural dinâmica quando comparada com métodos tradicionais. A análise dinâmica linear em elementos finitos, o cálculo de sensibilidades do problema e a etapa de otimização são realizados por meio de rotinas programadas em MATLAB ${ }^{\circledR}$. Um interface com o programa ANSYS ${ }^{\circledR}$ foi desenvolvida onde as respostas podem ser obtidas e importadas para o programa desenvolvido em MATLAB ${ }^{\circledR}$.

\section{4}

\section{Organização da Dissertação}

Essa dissertação divide-se em 5 capítulos. O Capítulo 2 apresenta uma revisão sobre elementos finitos e o método de integração no tempo utilizado neste trabalho, e ao final do capítulo é feita a validação da implementações feitas com o auxílio de um programa comercial de análise em elementos finitos. O Capítulo 3 trata do desenvolvimento das equações de análise de sensibilidade, necessárias para diminuir o custo computacional gasto com o cálculo numérico das mesmas. Os resultados são verificados com os obtidos utilizado-se o programa Ansys ${ }^{\circledR}$. O Capítulo 4 apresenta a otimização estrutural dinâmica utilizando o método do carregamento estático equivalente, deduz as equações necessárias para sua implementação e apresenta problemas clássicos de treliça utilizando o método ESL para a resolução da otimização sujeita a carregamentos dinâmicos. Por fim, o Capítulo 5 reúne as conclusões e apresenta as sugestões para trabalhos futuros. 


\section{2 \\ Desenvolvimento Teórico}

Neste capítulo, é realizada uma revisão dos tópicos necessários para a formulação de um problema de otimização estrutural dinâmica. Primeiramente, a discretização da estrutura contínua em elementos finitos é realizada de modo a resolver o sistema de equações diferenciais que modelam a resposta dinâmica da estrutura em todos os seus nós. De acordo com o método dos elementos finitos, são obtidas as matrizes globais de rigidez, massa e amortecimento, utilizadas na resolução do sistema matricial encontrado. Em seguida, as equações diferenciais são integradas no domínio do tempo e as respostas dinâmicas do sistema são obtidas. A partir de tais respostas, como deslocamentos, as equações de restrições podem ser formuladas no problema de otimização estrutual. Para a integração do sistema de equações diferenciais, o método de Newmark [23] é utilizado.

\section{1}

\section{Revisão de Elementos Finitos}

Nesta seção uma revisão dos conceitos básicos do método dos elementos finitos é feita partindo da equação que governa o comportamento dinâmico de um sistema, ou seja:

$$
\mathbf{M} \ddot{\mathbf{u}}(t)+\mathbf{C} \dot{\mathbf{u}}(t)+\mathbf{K u}(t)=\mathbf{F}(t)
$$

onde $\mathbf{M}, \mathbf{C}, \mathbf{K}$ e representam as matrizes de massa, amortecimento e rigidez, respectivamente, $\mathbf{F}$ o vetor de forças transientes externas aplicadas, $\mathbf{u}$, $\mathbf{u}$ e $\ddot{\mathbf{u}}$ correspondem aos deslocamentos, velocidades e acelerações ao longo do tempo. A técnica de elementos finitos divide a estrutura original contínua em uma malha formada por pontos nodais, ou simplesmente nós. Os nós, por sua vez delimitam elementos, podendo ser lineares, planos ou espaciais. A cada nó são atribuídos um ou mais graus de liberdade que representam as naturezas físicas do sistema discretizado, isto é, deslocamentos e rotações, entre outros. A Figura (2.1) apresenta exemplos de elementos finitos de uma, duas e três dimensões. Devido à disposição dos elementos ao longo da malha, as matrizes necessárias são geradas para cada elemento, considerando uma enumeração 
local dos seus graus de liberdade. Após o cálculo para todos os elementos, as matrizes globais são montadas a partir composição das matrizes elementares e a Equação (2-1) está apta a ser resolvida para os vetores u em cada instante de tempo.
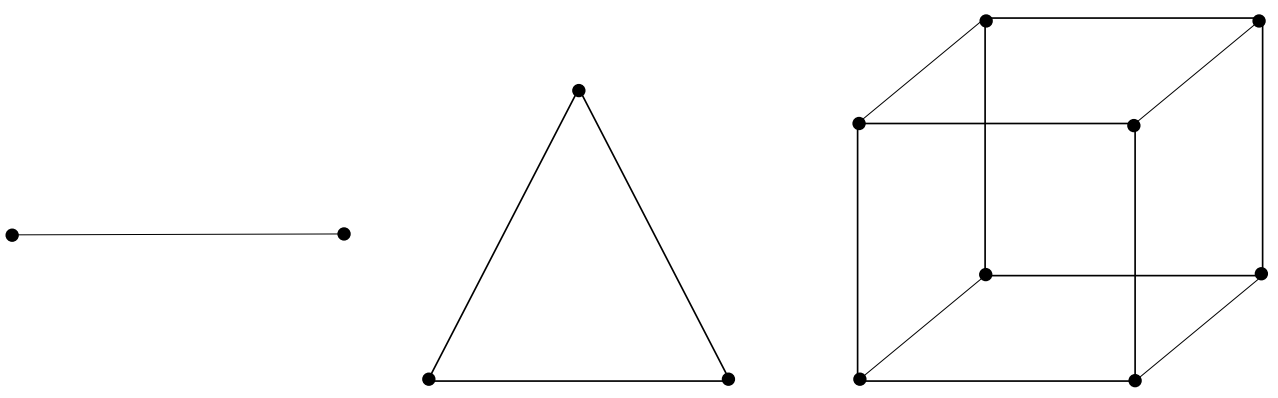

Figura 2.1: Elemento linear de 2 nós; elemento plano de 3 nós; elemento tridimensional de 8 nós.

As estruturas treliçadas mais simples são formuladas por elementos lineares unidimensionais, delimitados por 2 nós, um em cada extremidade. O emprego do método dos elementos finitos tem como objetivo neste trabalho obter as matrizes estruturais $\mathbf{K}, \mathbf{C}$ e $\mathbf{M}$. A seguir, vetores e matrizes associadas a esses elementos são determinados [24] de modo que a equação diferencial em (2-1) possa ser integrada e a resposta ao forçamento dinâmico obtido.

A formulação em elementos finitos requer que primeiramente seja estabelececida uma relação entre as coordenadas do sistema contínuo e o discretizado, e a matriz de forma $\mathbf{N}$ estabelece que:

$$
\mathbf{N}(x)=\left[\begin{array}{cccc}
1-\frac{x}{L} & 0 & \frac{x}{L} & 0 \\
0 & 1-\frac{x}{L} & 0 & \frac{x}{L}
\end{array}\right]
$$

onde os elementos de $\mathbf{N}$ contém as parametrizações que relacionam os deslocamentos medidos em um sistema de coordenadas $\mathbf{u}(t)$ com os deslocamentos dos pontos nodais da malha gerada $\mathbf{u}_{e}$, de modo que:

$$
\mathbf{u}(x, t)=\mathbf{N}(x) \mathbf{u}_{e}(t)
$$

Através da Equação (2-3) é possível mapear qualquer ponto intermediário contínuo compreendido entre os nós do elemento. As parametrizações contidas na matriz de forma são chamadas funções de forma e são construídas de tal forma que valem 1 no nó correspondente à função e 0 nos demais nós [23]. 


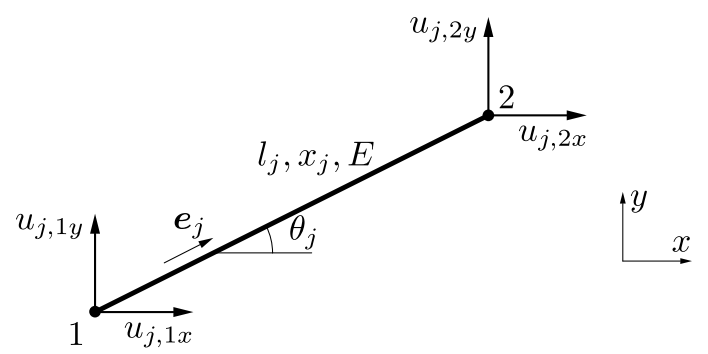

Figura 2.2: Elemento de barra escrito em um sistema de referências local $\{\mathbf{u}, \mathbf{v}\}$ com coordenadas projetadas em um outro sistema $\{\mathbf{x}, \mathbf{y}\}$.

A deformação normal em um elemento de treliça alinhado ao eixo $x$ é dada por:

$$
\epsilon_{x}=\frac{\partial u}{\partial x}
$$

A Equação (2-4) deve ser reescrita em forma matricial. A matriz que relaciona os deslocamentos nodais com deformação no elemento é obtida por meio da diferenciação de $\mathbf{N}$ com respeito à $x$. Elementos de treliça, ou unidimensionais, são caracterizados por só apresentarem rigidez na direção axial, de modo que se desconsidera a rigidez nas demais direções. Portanto, a matriz de deslocamento-deformação é escrita como:

$$
\mathbf{B}=\frac{1}{L}\left[\begin{array}{rrrr}
-1 & 0 & 1 & 0 \\
0 & -1 & 0 & 1
\end{array}\right]
$$

Onde $L$ é o comprimento do elemento. A tensão axial é definida pela equação constitutiva que relaciona tensão e deformação por meio de:

$$
\sigma(t)=\frac{E}{L}\left[\begin{array}{llll}
-c_{x} & -c_{y} & c_{x} & c_{y}
\end{array}\right] \mathbf{u}_{e}(t)
$$

onde $c_{x}$ e $c_{y}$ são os cossenos diretores, como será visto ainda nesta seção, e a matriz constitutiva se reduz ao escalar $E$. As matrizes locais de rigidez e massa, $\mathbf{k}_{e}$ e $\mathbf{m}_{e}$ respectivamente, definidas pela integral no volume do elemento, podem ser escritas em forma matricial como:

$$
\begin{aligned}
& \mathbf{k}_{e}=\int_{V} \mathbf{B}^{T} E \mathbf{B} d V \\
& \mathbf{m}_{e}=\int_{V} \rho \mathbf{N}^{T} \mathbf{N} d V
\end{aligned}
$$




$$
\begin{gathered}
\mathbf{k}_{e}=\frac{E A}{L}\left[\begin{array}{rrrr}
1 & 0 & -1 & 0 \\
0 & 0 & 0 & 0 \\
-1 & 0 & 1 & 0 \\
0 & 0 & 0 & 0
\end{array}\right] \\
\mathbf{m}_{e}=\frac{\rho A L}{6}\left[\begin{array}{llll}
2 & 0 & 1 & 0 \\
0 & 2 & 0 & 1 \\
1 & 0 & 2 & 0 \\
0 & 1 & 0 & 2
\end{array}\right],
\end{gathered}
$$

onde a densidade $\rho$ é constante ao longo do elemento. A matriz de amortecimento (Chopra [25]) é definida por:

$$
\mathbf{c}_{e}=\int_{V} c(x) \mathbf{N}^{T} \mathbf{N} d V
$$

Todavia, a obtenção da função $c(x)$ não é trivial. Uma forma de representar o amortecimento viscoso é por meio do método de Rayleigh de amortecimento proporcional, onde:

$$
\mathbf{c}_{e}=\alpha \mathbf{m}_{e}+\beta \mathbf{k}_{e}
$$

As expressões para $\alpha$ e $\beta$ são obtidas por meio do fator de amortecimento e de duas frequências naturais distintas:

$$
\begin{aligned}
& \alpha=\xi \frac{2 \omega_{1} \omega_{2}}{\omega_{1}+\omega_{2}} \\
& \beta=\xi \frac{2}{\omega_{1}+\omega_{2}},
\end{aligned}
$$

onde $\omega_{1}$ e $\omega_{2}$ são as frequências naturais de 2 modos de vibração e o fator de amortecimento $\xi$ pode ser assumido como o mesmo para dois modos, se escolhidos de forma que não haja grande discrepância no valor do fator de amortecimento de cada modo envolvido na resposta do sistema.

Para obter as matrizes de rigidez e de massa em coordenadas globais, a matriz de rotação $\mathbf{R}$ é necessária. Ela é preenchida com os cossenos diretores que relacionam dois sistemas de coordenadas defasados de um ângulo de rotação $\theta_{j}$ (Figura 2.2):

$$
\mathbf{R}=\left[\begin{array}{rr}
c_{x} & c_{y} \\
-c_{y} & c_{x}
\end{array}\right]
$$




$$
\hat{\mathbf{R}}=\left[\begin{array}{cc}
\mathbf{R} & 0 \\
0 & \mathbf{R}
\end{array}\right]
$$

onde a matriz $\hat{\mathbf{R}}$ é montada a partir de $\mathbf{R}$ de maneira a ajustar as dimensões para a obtenção das matrizes dos elementos em coordenadas globais $\overline{\mathbf{K}}$ e $\overline{\mathbf{M}}$ :

$$
\begin{aligned}
\overline{\mathbf{K}} & =\hat{\mathbf{R}}^{T} \mathbf{k}_{e} \hat{\mathbf{R}} \\
\overline{\mathbf{M}} & =\hat{\mathbf{R}}^{T} \mathbf{m}_{e} \hat{\mathbf{R}}
\end{aligned}
$$

Uma vez calculadas as matrizes de todos os elementos já estando representadas no sistema global, as matrizes estruturais globais são montadas a partir das contribuições de cada elemento, de forma que:

$$
\begin{array}{r}
\mathbf{K}=\sum_{e=1}^{N_{e}} \overline{\mathbf{K}}_{e} \\
\mathbf{M}=\sum_{e=1}^{N_{e}} \overline{\mathbf{M}}_{e}
\end{array}
$$

Nas Equações (2-19) e (2-20), as composições das matrizes globais são feitas correlacionando os graus de liberdade globais da estrutura com os graus de liberdade locais de cada elemento. Dessa forma, as contribuições dos graus de liberdade de elementos que compartilham o mesmo nó são acumulados adequadamente nas matrizes globais.

\section{2}

\section{Integração no Tempo}

A equação diferencial descrita em (2-1) precisa ser resolvida de modo a se obter a resposta dinâmica do sistema. A complexidade do problema inviabiliza uma integração analítica, portanto um método de integração numérica é implementado. Neste trabalho, o método de Newmark é utilizado [26]. O método de Newmark é um método implícito de integração direta, e tem como vantagem sobre métodos de análise modal a possibilidade de tratar problemas tanto lineares quanto não lineares sem dificuldades. Métodos de análise modal geralmente apresentam problemas para lidar com não linearidades . 
O método de Newmark parte da definição das seguintes equações para os deslocamentos e velocidades num instante $t$ :

$$
\begin{gathered}
\mathbf{u}_{1}=\mathbf{u}_{0}+\Delta t \mathbf{v}_{0}+\frac{1}{2}\left(\Delta t^{2}\right)\left[2 \beta \mathbf{a}_{1}+(1-2 \beta) \mathbf{a}_{0}\right] \\
\mathbf{v}_{1}=\mathbf{v}_{0}+\Delta t\left[\gamma \mathbf{a}_{1}+(1-\gamma) \mathbf{a}_{0}\right]
\end{gathered}
$$

onde $\mathbf{u}_{0}$ e $\mathbf{u}_{1}$ são os deslocamentos (o mesmo se aplica para velocidades e acelerações) nos instantes atual $t$, onde os deslocamentos são conhecidos, e $t+\Delta t$, a serem obtidos. Neste método, são definidos os parâmetros $\beta$ e $\gamma$ necessários para conferir estabilidade e convergência, além de definir o método de aproximação para aceleração [25]. Quando $\beta=0$, é considerada aceleração constante; $\beta=\frac{1}{4}$ considera aceleração média; por fim, $\beta=\frac{1}{6}$ considera aceleração linear. A Figura (2.3) ilustra a interpretação da variação do tipo de aceleração com a alteração do parâmetro $\beta$. O parâmetro $\gamma$ rege a presença de amortecimento numérico no método. Assim, se $\gamma=\frac{1}{2}$ o método se mostra livre de amortecimentos, enquanto que $\gamma>\frac{1}{2}$ e $\gamma<\frac{1}{2}$ conferem, respectivamente, amortecimento positivo e negativo durante a integração. Inicialmente definemse:

$$
\begin{gathered}
\overline{\mathbf{u}}=\mathbf{u}_{0}+\Delta t \mathbf{v}_{0}+\frac{1}{2} \Delta t^{2}(1-2 \beta) \mathbf{a}_{0} \\
\overline{\mathbf{v}}=\mathbf{v}_{0}+\Delta t(1-\gamma) \mathbf{a}_{0},
\end{gathered}
$$

denominados preditores. As duas equações acima são as parcelas das Equações (2-21) e (2-22) dependentes do instante de tempo atual. O vetor de aceleração inicial pode ser obtida por meio da equação da resposta dinâmica com as condições iniciais. A substituição das Equações (2-23) e (2-24) na Equação (2-1) resulta em:

$$
\left[\mathbf{M}+\mathbf{C} \Delta t \gamma+\mathbf{K} \Delta t^{2} \beta\right] \mathbf{a}_{1}=\mathbf{F}_{1}-\mathbf{C} \overline{\mathbf{v}}-\mathbf{K} \overline{\mathbf{u}}
$$

A solução da Equação (2-25) fornece o vetor de aceleração do instante $t+$ $\Delta t$. Por fim, utilizando os termos preditores e $\mathbf{a}_{1}$, são obtidos os deslocamentos e velocidadaes como:

$$
\begin{aligned}
& \mathbf{u}_{1}=\overline{\mathbf{u}}+\Delta t^{2} \beta \mathbf{a}_{1} \\
& \mathbf{v}_{1}=\overline{\mathbf{v}}+\Delta t \gamma \mathbf{a}_{1}
\end{aligned}
$$


No método de Newmark, os vetores chamados preditores $\overline{\mathbf{u}}$ e $\overline{\mathbf{v}}$ são escritos em função dos valores de deslocamento, velocidade e aceleração no instante atual, conhecidos. $\mathrm{O}$ vetor de aceleração aceleração $\mathbf{a}_{1}$ no instante de tempo $t+\Delta t$ é calculado em função dos termos preditores e por fim são calculados os deslocamentos e velocidades. Para mais referências sobre o método de Newmark, o leitor pode consultar Bathe [23], Cook [27] e Rajasekaran [28].
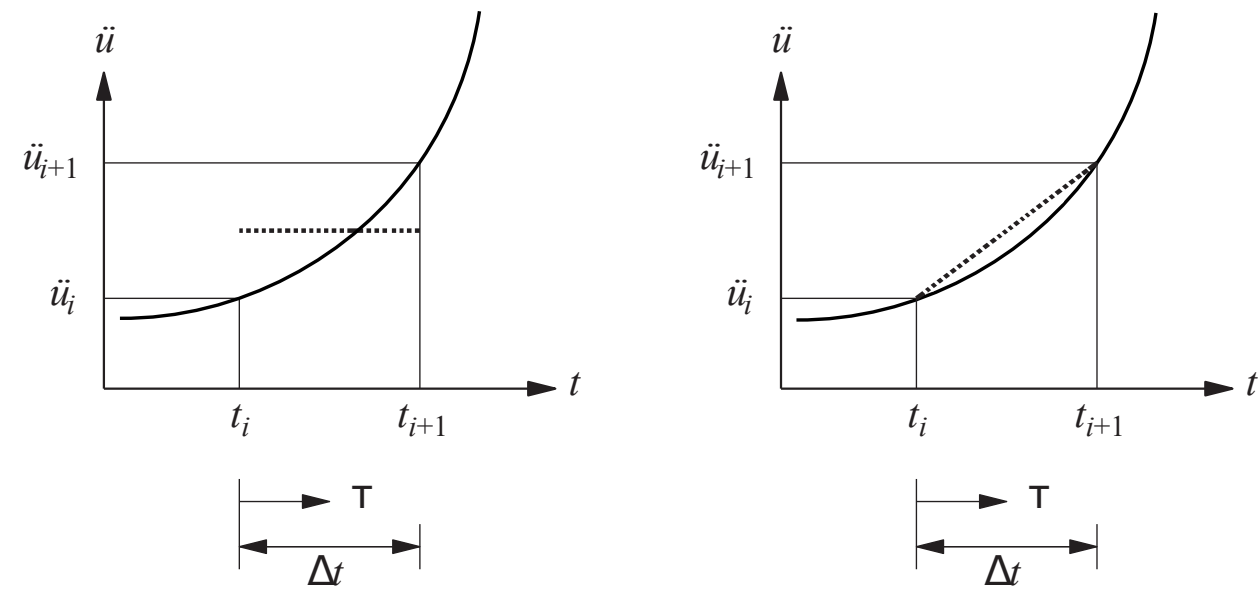

Figura 2.3: Aceleração média constante (à esquerda) e linear (à direita) pelo método de Newmark.

\section{3}

\section{Verificação da Análise Dinâmica}

Nesta seção, o emprego dos métodos de elementos finitos e integração numérica no tempo por meio das equações de Newmark são comparados com exemplos encontrados na literatura. Ambos os métodos foram incorporados em uma rotina computacional implementada em MATLAB ${ }^{\circledR}$. Primeiro são obtidas as matrizes globais de massa e rigidez atravéz da montagem das matrizes elementares. Em seguida, de posse das matrizes do sistema a equação discretizada é integrada por meio do método de Newmark. A Figura (2.4) ilustra o processo.

O problema a seguir, encontrado em Weaver \& Johnston [24], apresenta uma treliça de 3 barras com um apoio móvel no nó 1 e um apoio rotulado no nó 2, Figura (2.5). A treliça está submetida a um carregamento $P(t)$ linear por partes e contém apoios de primeia e segunda ordem nos nós 1 e 2. É desejado obter as respostas dinâmicas do deslocamento e tensão axial. Dados

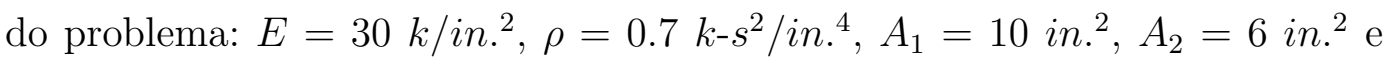
$A_{3}=8$ in. $^{2}$ 


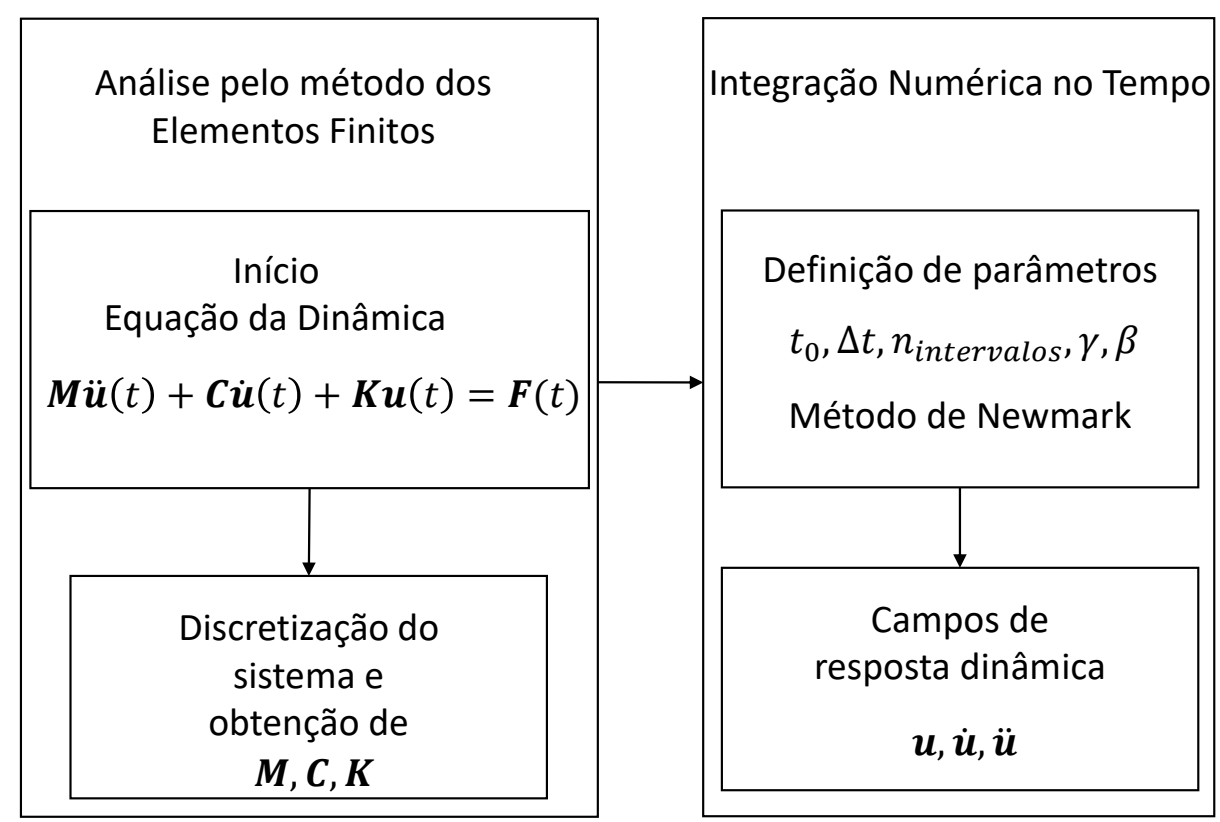

Figura 2.4: Processo de solução da análise dinâmica via método dos elementos finitos e método de Newmark.
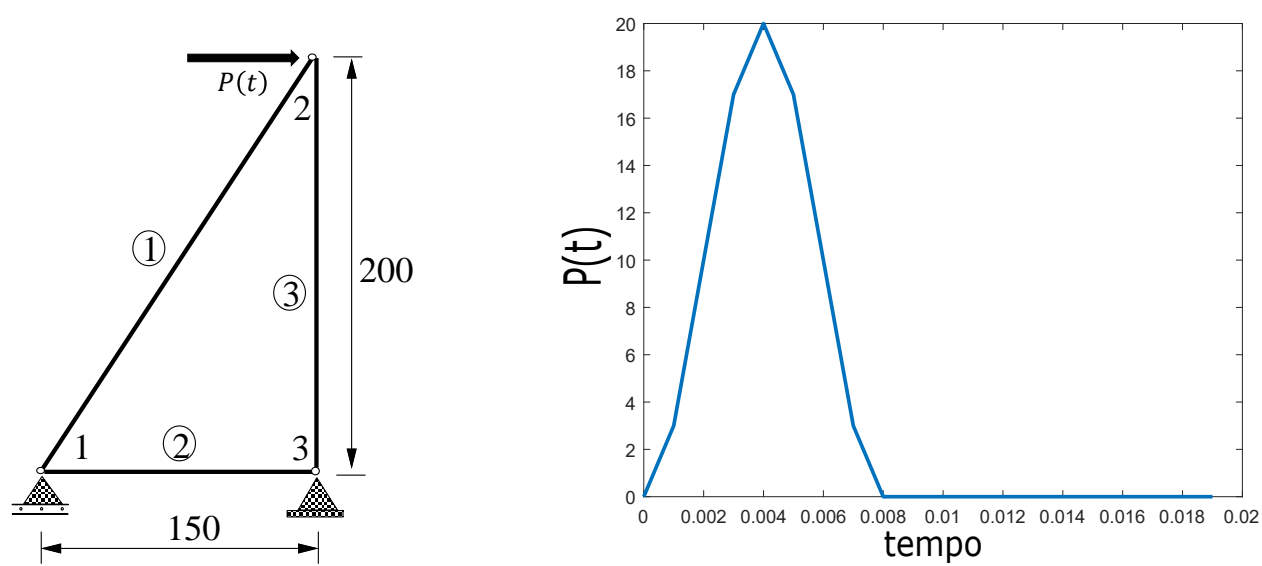

Figura 2.5: Treliça de 3 elementos. Figura 2.6: Carregamento linear por partes $P(t)$.

Para a verificação da rotina de análise dinâmica implementada, o problema foi resolvido por meio do software de elementos finitos ANSYS $^{\circledR}$. As Figuras (2.7) e (2.8) apresentam as respostas dinâmicas dos campos de deslocamento horizontal do nó 2 da estrutura e tensão axial no elemento 1, obtidas pelas análises via ANSYS $^{\circledR}$ e o código implementado em MATLAB ${ }^{\circledR}$ em linhas cheia e pontilhada, respectivamente. 


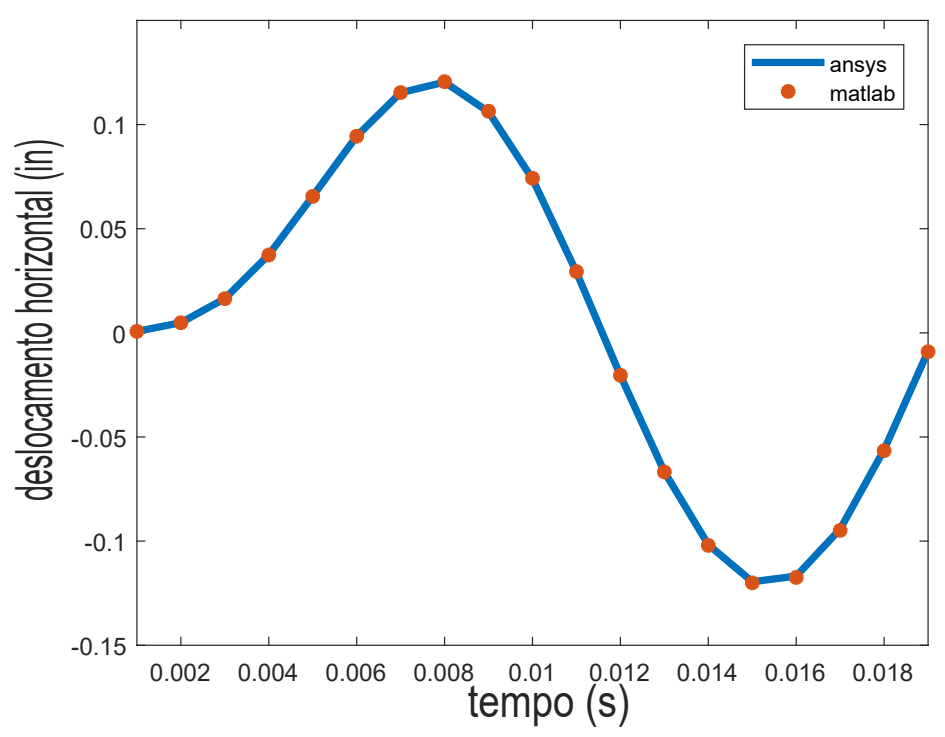

Figura 2.7: Resposta do deslocamento horizontal do nó 2.

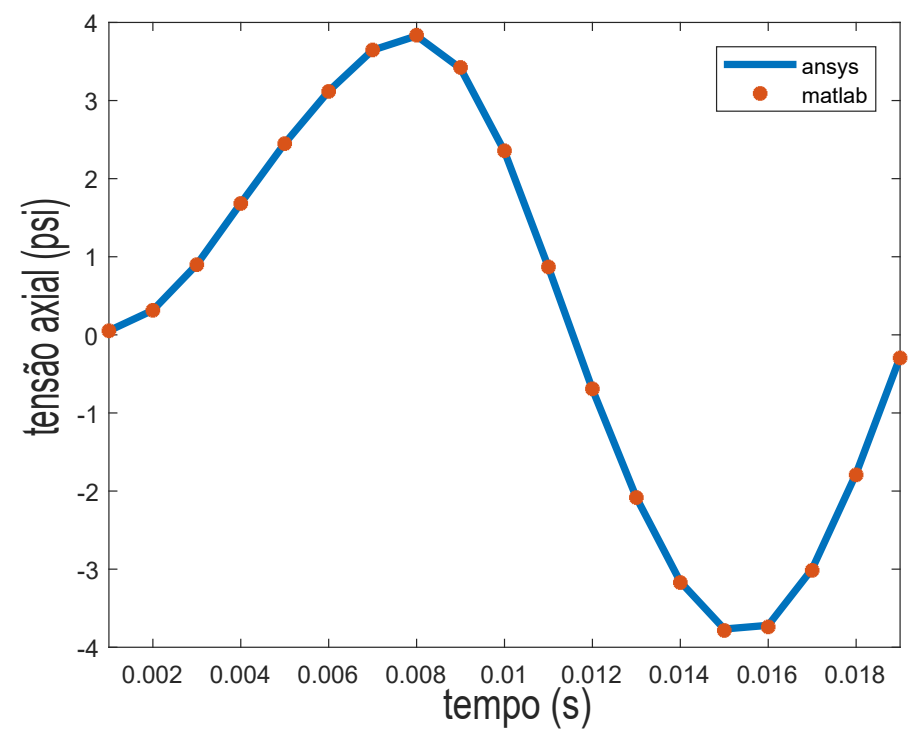

Figura 2.8: Tensão axial no elemento 1. 


\section{3}

\section{Análise de Sensibilidade}

A análise de sensibilidade se faz necessária na avaliação da direção de busca em problemas de otimização que utilizam algoritmos de primeira ordem. A literatura mostra que o custo com o cálculo das derivadas das respostas estruturais do sistema, presentes nas restrições e função objetivo, com relação às variáveis de projeto são parte considerável, quando não a maioria, do tempo gasto e poder de processamento utilizado pelos computadores durante a solução do problema. Em problemas estruturais com restrições dependentes do tempo, esse problema é ainda mais impactante, às vezes tornando a resolução do problema inviável devido ao grande número de derivadas a se calcular. Portanto, há bastante necessidade de se implementar técnicas e métodos eficientes que minimizem essa demanda de tempo e processamento na rotina de otimização.

Neste capítulo são apresentadas 3 técnicas bastante utilizadas em problemas de otimização estrutural para a obtenção das sensibilidades: o método de diferenças finitas e os métodos analíticos direto e adjunto. Cada método tem suas equações e desenvolvimentos apresentados, vantagens e desvantagens são colocadas, bem como quando suas aplicações são mais eficientes. Ao final, exemplos são apresentados para verificar a implementação do método analítico direto para cálculo de sensibilidades.

\section{1}

\section{Diferenças Finitas}

No método das diferenças finitas, os termos de derivadas presentes na equação diferencial são substituídas por aproximações feitas avaliando a função em pontos específicos. Seja $f(b)$ uma função de uma única variável $b$. A derivada de $f$ avaliada em $b$ é aproximada por diferenças finitas em torno da vizinhança de $b$, com uma variação $h$ da seguinte forma (Arora [29]):

$$
f^{\prime}(b) \approx \frac{f(b+h)-f(b)}{h}
$$

neste caso, foi utilizada diferença à frente, pois a derivada foi aproximada por meio da diferença entre um ponto vizinho $b+h$ à frente de $b$. Da mesma 
forma, é possível se obter a derivada de $f(b)$ por duas outras aproximações, com diferença para trás e diferença central, Equações (3-2) e (3-3):

$$
\begin{gathered}
f^{\prime}(b) \approx \frac{f(b)-f(b-h)}{h} \\
f^{\prime}(b) \approx \frac{f(b+h)-f(b-h)}{2 h}
\end{gathered}
$$

Pela aproximação por diferença à frente, a derivada de $f(b)$ é calculada pela diferença de $f$ avaliada em $b$ e $b+h$, dividido pelo passo $h$. Similarmente, na diferença para trás $f$ é avaliada nos pontos $b-h$ e $b$. A aproximação por diferenças centrais pode ser vista como a média entre as duas aproximações anteriores. A Figura (3.1) ilustra graficamente a interpretação geométrica das aproximações feitas nas Equações (3-1), (3-2) e (3-3).

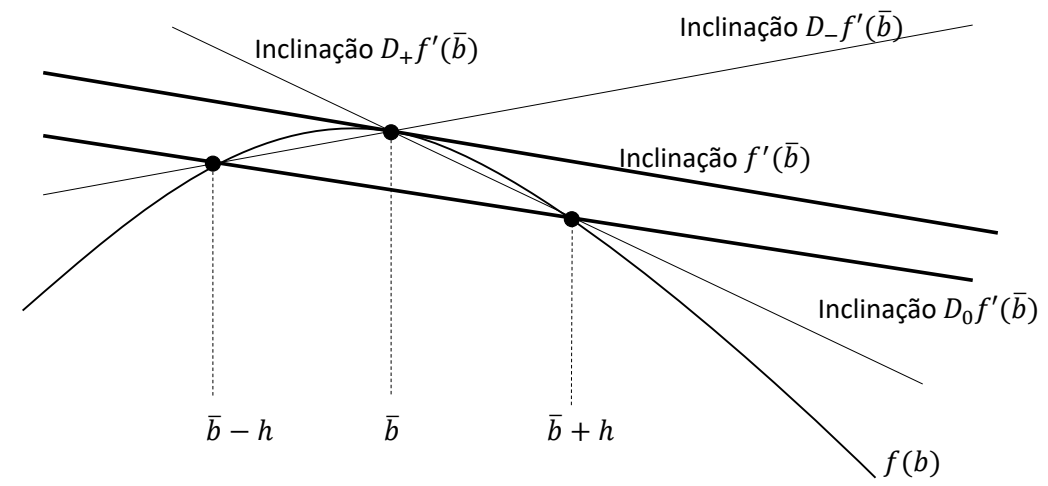

Figura 3.1: Aproximações por diferenças finitas: diferença à frente (Eq. (3-1)), para trás (Eq. (3-2)) e central (Eq. (3-3)).

O método das diferenças finitas possui como principal vantagem a fácil implementação. Isso se deve ao fato do método não precisar realizar nenhum cálculo diferencial para obter a derivada da função, sendo suficiente apenas a avaliação da função original em sua vizinhança. Esse é um motivo pelo qual este método é vastamente usado em problemas de engenharia, e possui um grande apelo na aplicação em problemas que possuem maiores complexidadses na determinação das sensibilidades do sistema.

Em contrapartida, existem limitações para o uso deste método que podem inviabilizá-lo, inerentes à escolha do passo $h$. Para melhor ilustrar essa limitação, a Equação (3-4) mostra uma aproximação por diferenças à frente com truncamento no segundo termo:

$$
f^{\prime}=\frac{f(b+h)-f(b)}{h}-\frac{h}{2} f^{\prime \prime}(b+\sigma h), \quad 0 \leq \sigma \leq 1
$$


A fim de diminuir o erro de truncamento, é intuitivo propor a redução do passo $h$. Porém esta ação cria erros de condicionamento, que são erros associados ao primeiro termo à direita da igualdade da Equação (3-4), ao passo que aumentar o valor de $h$ aumentará o erro de truncamento, segundo termo da Equação (3-4). Sendo assim, a implementação de outras técnicas de avaliação de derivadas se faz presente e elas são vistas nas seções seguintes.

\section{2}

\section{Métodos Analíticos para Análise de Sensibilidade}

Destacados por um menor custo computacional com o cálculo das derivadas, métodos analíticos para análise de sensibilidade de problemas estruturais possuem um maior esforço de implementação, porém em retorno acelera a computação de derivadas e evita os problemas presentes no métodos de aproximação por diferenças finitas. Estes métodos são divididos em direto e adjunto, cada um deles conferindo vantagens ou desvantagens dependendo do número de restrições e variáveis de projeto do problema de otimização estrutural a ser solucionado.

\subsection{1}

\section{Método de Diferenciação Direta}

Primeiramente as equações de análise de sensibilidade são deduzidas [33] para a análise estática estrutural de um sistema discretizado em elementos finitos, regida pela equação:

$$
\mathbf{K}(\mathbf{b}) \mathbf{u}(\mathbf{b})=\mathbf{F}(\mathbf{b})
$$

onde $\mathbf{K}(\mathbf{b})$, é a matriz de rigidez da estrutura, $\mathbf{u}$ é o vetor dos deslocamentos nodais e F é o vetor de carregamentos aplicados à estrutura. Seja (3-6) a definição de um vetor de restrições $\mathbf{g}$ :

$$
g_{i}=g_{i}(\mathbf{b}, \mathbf{u}(\mathbf{b})) \leq 0, i=1 \ldots m
$$

onde $\mathbf{g}$ possui termos explicitamente e implicitamente dependentes de $\mathbf{b}$. Derivando as Equações (3-5) e (3-6) com respeito à b, temos:

$$
\mathbf{K} \frac{\partial \mathbf{u}}{\partial b_{j}}=\frac{\partial \mathbf{F}}{\partial b_{j}}-\frac{\partial \mathbf{K}}{\partial b_{j}} \mathbf{u}(\mathbf{b})
$$




$$
\frac{d g_{i}}{d b_{j}}=\frac{\partial g_{i}}{\partial b_{j}}+\frac{\partial g_{i}}{\partial \mathbf{u}} \frac{d \mathbf{u}}{d b_{j}}
$$

Assumindo que o vetor de carregamentos externos não depende de $\mathbf{b}$, $\frac{\partial \mathbf{F}}{\partial b_{j}}=0$, assim a Equação (3-7) se torna:

$$
\frac{d \mathbf{u}}{d b_{j}}=-\mathbf{K}^{-1}\left(\frac{\partial \mathbf{K}}{\partial b_{j}} \mathbf{u}(\mathbf{b})\right)
$$

Analisando as Equações (3-9) e (3-5), pode-se atribuir ao termo que é multiplicado pela matriz $\mathbf{K}^{-\mathbf{1}}$ o mesmo papel que o carregamento $\mathbf{F}$ desempenha na Equação (3-5). Devido a isso, este termo é comumente chamado de pseudo-carregamento. No método direto resolve-se o sub-problema estabelecido em (3-9) e em seguida resolve-se a Equação (3-8) uma vez para cada variável de projeto. Como é necessária a solução da equação de sensibilidade $n$ vezes, sendo $n$ o número de variáveis de projeto, esta abordagem do método analítico é mais eficiente quando o problema de otimização estrutural contém mais restrições do que variáveis de projeto, $m \geq n$.

\subsection{2}

\section{Método Adjunto ou Método do Espaço de Estado}

Substituindo a Equação (3-9) na Equação (3-8):

$$
\frac{d g_{i}}{d b_{j}}=\frac{\partial g_{i}}{\partial b_{j}}-\frac{\partial g_{i}}{\partial \mathbf{u}}\left(\mathbf{K}(\mathbf{b})^{-\mathbf{1}} \frac{\partial \mathbf{K}(\mathbf{b})}{\partial b_{j}} \mathbf{u}(\mathbf{b})\right)
$$

No método adjunto parte-se definindo um vetor adjunto $\lambda_{i}$ :

$$
\lambda_{i}=\left(\frac{\partial g_{i}}{\partial \mathbf{u}} \mathbf{K}(\mathbf{b})^{-\mathbf{1}}\right)^{T}
$$

E substituindo na Equação (3-10):

$$
\frac{d g_{i}}{d b_{j}}=\frac{\partial g_{i}}{\partial b_{j}}-\lambda_{i}^{T} \frac{\partial \mathbf{K}}{\partial b_{j}} \mathbf{u}(\mathbf{b})
$$

No método adjunto, a Equação (3-11) é resolvida uma vez para cada restrição do vetor $\mathbf{g}$. A equação depois é substituída na Equação (3-12) tantas vezes quanto for o valor de $n$. Logo, o método adjunto é mais eficaz que o direto quando houver menos restrições do que variáveis de projeto, ou seja, quando $m \leq n$. 


\subsection{3}

\section{Método de Newmark}

Na seção 2.2, o estudo da análise transiente de um sistema de múltiplos graus de liberdade, necessário para a formulação posterior do problema de otimização estrutural dinâmica, foi apresentado. O método de Newmark foi descrito e o conjunto de equações apresentadas são necessárias para obtenção das respostas dinâmicas do sistema, como deslocamentos, velocidades e acelerações, da estrutura discretizada ao longo dos intervalos de tempo da análise.

Na presente seção são deduzidas, por meio do método da diferenciação direta, as expressões para o cálculo das sensibilidades destas respostas dinâmicas, por meio das quais as sensibilidades das restrições dinâmicas são obtidas. Primeiramente são definidas as expressões para as derivadas de $\overline{\mathbf{v}}$ e $\overline{\mathbf{u}}$ :

$$
\begin{gathered}
\frac{\partial \overline{\mathbf{v}}}{\partial b}=\frac{\partial \mathbf{v}_{0}}{\partial b}+\Delta t(1-\gamma) \frac{\partial \mathbf{a}_{0}}{\partial b} \\
\frac{\partial \overline{\mathbf{u}}}{\partial b}=\frac{\partial \mathbf{u}_{0}}{\partial b}+\Delta t \frac{\partial \mathbf{v}_{0}}{\partial b}+\frac{1}{2} \Delta t^{2}(1-2 \beta) \frac{\partial \mathbf{a}_{0}}{\partial b}
\end{gathered}
$$

Derivando a Equação (2-25) com respeito à $b$ e substituindo as Equações (3-13) e (3-14), a derivada da equação da dinâmica fica:

$$
\begin{aligned}
& {\left[\mathbf{M}+\mathbf{C} \Delta t \gamma+\mathbf{K} \Delta t^{2} \beta\right] \frac{\partial \mathbf{a}_{1}}{\partial b}=\frac{\partial \mathbf{P}_{1}}{\partial b}-\frac{\partial \mathbf{C}}{\partial b} \overline{\mathbf{v}}-\mathbf{C} \frac{\partial \overline{\mathbf{v}}}{\partial b}-\frac{\partial \mathbf{K}}{\partial b} \overline{\mathbf{u}}-\mathbf{K} \frac{\partial \overline{\mathbf{u}}}{\partial b}+} \\
& -\left[\frac{\partial \mathbf{M}}{\partial b}+\frac{\partial \mathbf{C}}{\partial b} \Delta t \gamma+\frac{\partial \mathbf{K}}{\partial b} \Delta t^{2} \beta\right] \mathbf{a}_{1}
\end{aligned}
$$

O processo para se obter as derivadas para todos os instantes de tempo se dá de modo semelhante ao apresentado na seção 2.2. Após uma manipulação algébrica, é possível reescrever a Equação (3-15) em função de $\mathbf{u}_{1}, \mathbf{v}_{1}$ e $\mathbf{a}_{1}$ :

$$
\begin{aligned}
& {\left[\mathbf{M}+\mathbf{C} \Delta t \gamma+\mathbf{K} \Delta t^{2} \beta\right] \frac{\partial \mathbf{a}_{1}}{\partial b}=\frac{\partial \mathbf{P}_{1}}{\partial b}-\frac{\partial \mathbf{C}}{\partial b} \mathbf{v}_{1}-\mathbf{C} \frac{\partial \overline{\mathbf{v}}}{\partial b}+} \\
& -\frac{\partial \mathbf{K}}{\partial b} \mathbf{u}_{1}-\mathbf{K} \frac{\partial \overline{\mathbf{u}}}{\partial b}-\frac{\partial \mathbf{M}}{\partial b} \mathbf{a}_{1}
\end{aligned}
$$

A Equação (3-16) permite calcular a derivada da aceleração no instante 
$t_{1}$ com respeito à $b$, e por fim as derivadas da velocidade e deslocamento para o mesmo instante de tempo são calculadas a partir de:

$$
\begin{gathered}
\frac{\partial \mathbf{v}_{1}}{\partial b}=\frac{\partial \overline{\mathbf{v}}}{\partial b}+\Delta t \gamma \frac{\partial \mathbf{a}_{1}}{\partial b} \\
\frac{\partial \mathbf{u}_{1}}{\partial b}=\frac{\partial \overline{\mathbf{u}}}{\partial b}+\Delta t^{2} \beta \frac{\partial \mathbf{a}_{1}}{\partial b}
\end{gathered}
$$

Os valores dos deslocamentos, velocidades e acelerações em cada instante de tempo devem ser calculadas previamente para serem fornecidas às equações de sensibilidade de Newmark.

A matriz de massa definida na Equação (2-18), para uma estrutura discretizada, é calculada por meio de um somatório envolvendo todos os elementos:

$$
\mathbf{M}=\sum_{e=1}^{N_{e}} \rho_{e} \mathbf{N}^{T} \mathbf{N} A_{e} l_{e}
$$

E, derivando em relação à variável $b_{j}$ tem-se:

$$
\begin{aligned}
& \frac{\partial \mathbf{M}}{\partial b_{j}}=\sum_{e=1}^{N_{e}}\left(\frac{\partial \rho_{e}}{\partial b_{j}} \mathbf{N}^{T} \mathbf{N} A_{e} l_{e}+\rho_{e} \frac{\partial \mathbf{N}^{T}}{\partial b_{j}} \mathbf{N} A_{e} l_{e}+\rho_{e} \mathbf{N}^{T} \frac{\partial \mathbf{N}}{\partial b_{j}} A_{e} l_{e}+\right. \\
& \left.\rho_{e} \mathbf{N}^{T} \mathbf{N} \frac{\partial A_{e}}{\partial b_{j}} l_{e}+\rho_{e} \mathbf{N}^{T} \mathbf{N} A_{e} \frac{\partial l_{e}}{\partial b_{j}}\right)
\end{aligned}
$$

Dependendo da variável de projeto do problema, certas simplificações são feitas e um ou mais termos desta equação desaparecem. O caminho para a formulação geral da sensibilidade da matriz de rigidez se dá de maneira análoga à demonstrada acima, contudo, a dedução para a derivada da matriz de rigidez em relação à variável de projeto $b_{j}$ para um problema onde as áreas de seção reta são as variáveis do problema é feita na próxima seção e as interpretações necessárias para as simplificações aqui mencionadas são desenvolvidas. 


\subsection{4}

\section{Verificação do Método Direto}

Para otimização dinâmica de estruturas treliçadas, foco deste trabalho, o método analítico direto é aplicado para o cálculo das sensibilidades, uma vez que o número de restrições é muito maior que o número de variáveis de projeto e o método direto é mais eficiente que o adjunto nesse contexto.

Para ilustrar a aplicação do método, considere uma restrição de tensão, comumente representada por:

$$
g(t)=\frac{\sigma(t)}{\bar{\sigma}}-1 \leq 0
$$

Tomando a derivada com respeito à b, a derivada da restrição $g$ fica em função da derivada da tensão:

$$
\frac{\partial g(t)}{\partial b_{j}}=\frac{1}{\bar{\sigma}} \frac{\partial \sigma(t)}{\partial b_{j}}
$$

A diferenciação da equação constitutiva (2-6) fornece:

$$
\frac{\partial \sigma(t)}{\partial b_{j}}=\frac{E_{e}}{l_{e}}\left[\begin{array}{llll}
-c_{x} & -c_{y} & c_{x} & c_{y}
\end{array}\right] \frac{\partial \mathbf{u}_{e}(t)}{\partial b_{j}}
$$

Para se obter analiticamente a sensibilidade dos deslocamentos é necessário saber antes a sensibilidade deste pseudo-carregamento com respeito à b. A Equação (3-24) indica esta relação:

$$
\frac{\partial \mathbf{K}}{\partial b_{j}} \mathbf{u}(\mathbf{b})=\sum_{e=1}^{n_{e}} \mathbf{B}_{e}^{T} E_{e} \mathbf{B}_{e} \frac{\partial A_{e}}{\partial b_{j}} l_{e} \mathbf{u}(\mathbf{b})
$$

Considerando que as variáveis de projeto $b_{j}$ são as áreas $A_{e}$, a única componente remanescente da diferenciação via regra da cadeia é exatamente o termo à direita da igualdade na Equação (3-24). Os demais termos estariam associados com como $\mathbf{B}_{e}, E_{e}$ e $l_{e}$ variam para uma dada variação da área de seção reta da treliça. Nenhum desses termos apresenta este tipo de variação, o que justifica o único termo restante ser exatamente o que envolve variações das próprias áreas.

Segundo a formulação em elementos finitos para elementos de treliça, cada barra é composta por um único elemento, e por isso todos os elementos 
possuem, em geral, um valor constante para a sua área de seção reta. Disso, conclui-se que:

$$
\frac{\partial \mathbf{K}}{\partial b_{j}}= \begin{cases}E_{e} \mathbf{B}_{e}^{T} \mathbf{B}_{e} l_{e} & \text { se } j=e \\ 0 & \text { se } j \neq e\end{cases}
$$

Pois, como cada elemento é relacionado a apenas uma área, os termos do somatório da Equação (3-24) existem somente quando o índice do elemento $e$ coincide com o índice $j$, da derivada da matriz de rigidez global. Como a área é a própria variável de projeto, o termo associado à derivada parcial dentro do somatório se torna unitário. Portanto, a derivada da matriz de rigidez global com respeito à variável $b_{j}$ é preenchida apenas com os elementos obtidos da derivada da matriz de rigidez do elemento $e$ tal que $e=j$.

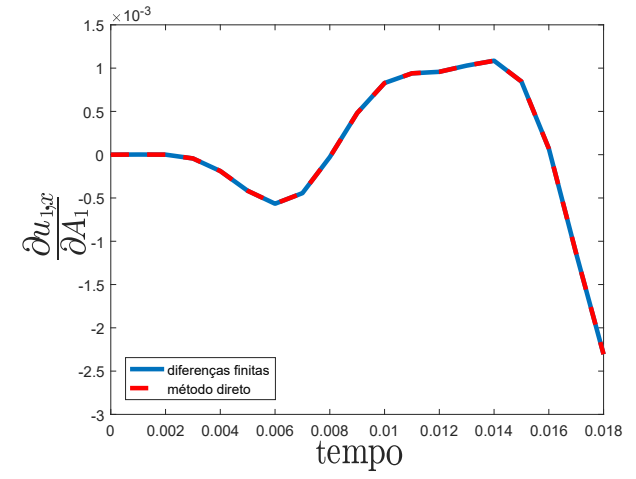

Figura 3.2: Derivada do deslocamento horizontal do nó 1 com respeito à área do elemento 1 ao longo do tempo.

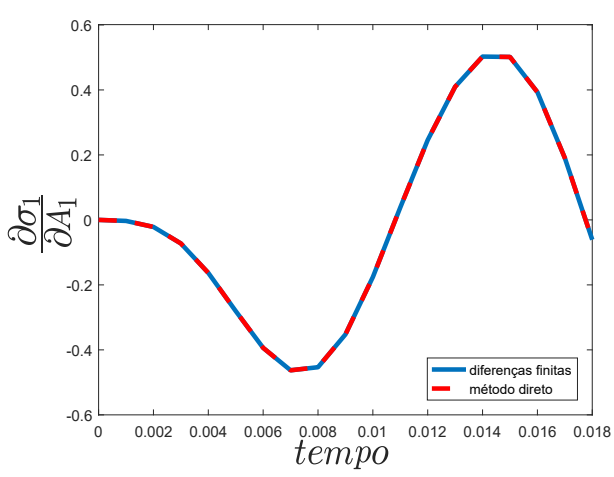

Figura 3.3: Derivada da tensão no elemento 1 com respeito à área do elemento 1 ao longo do tempo.

A seguir, a mesma treliça de 3 barras sujeita a um carregamento dinâmico [24], apresentada na seção 2.3, foi utilizada para a validação do método direto. A validação é feita por meio da comparação das sensibilidades obtidas com a aproximação das derivadas via diferenças finitas. A Figura (3.2) mostra como o deslocamento horizontal do nó 1 da treliça apresentada na Figura (2.5) varia com respeito à área do elemento 1 ao longo do tempo. Da mesma forma, a Figura (3.3) apresenta a derivada da tensão axial do elemento 1 em relação à sua própria área. Para os dois resultados, as sensibilidades calculadas pelo método direto e por diferenças finitas considerando um passo $h=10^{-7}$ foram as mesmas. 


\section{4 \\ Otimização Estrutural e o Método do Carregamento Estático Equivalente}

De posse do desenvolvimento teórico apresentado, este capítulo é dedicado à resolução de problemas envolvendo otimização estrutural com restrições que variam no tempo. Uma breve formulação do problema é apresentada, bem como técnicas bem conhecidas para lidar com restrições dinâmicas são descritas. Contudo, o principal objetivo do capítulo é o uso do método do carregamento estático equivalente como método de aproximação do problema original. A metodologia para geração dos carregamentos estáticos equivalentes (equivalent static loads, abreviado por ESL) é explicada em mais detalhes, e propriedades importantes do método, como a necessidade de atender às condições de primeira ordem na solução ótima, são apresentadas. Por fim, problemas envolvendo a otimização paramétrica de estruturas treliçadas são resolvidos. Os algoritmos desenvolvidos na dissertação utilizam uma integração entre dois programas de computador $\left(\right.$ ANSYS $^{\circledR}$ e MATLAB ${ }^{\circledR}$ ) para análise em elementos finitos e otimização, operando de forma alternada, cíclica e automatizada, até a solução ótima ser obtida.

\section{1}

\section{Formulação do Problema}

A formulação geral de um problema de otimização estrutural dinâmico é dada por:

$$
\begin{array}{ll}
\text { obter } & \mathbf{b} \\
\text { que minimize } & f(\mathbf{b}) \\
\text { sujeito a } & g_{j, t}(\mathbf{b}, \mathbf{u}(\mathbf{b}, t)) \leq 0, j=1, \ldots, m ; t=1, \ldots, n_{t} \\
& \mathbf{b}_{l} \leq \mathbf{b} \leq \mathbf{b}_{u} \\
\text { com } & \mathbf{M}(\mathbf{b}) \ddot{\mathbf{u}}(\mathbf{b}, t)+\mathbf{K}(\mathbf{b}) \mathbf{u}(\mathbf{b}, t)=\mathbf{F}(t)
\end{array}
$$

onde $\mathbf{b}$ é o vetor de variáveis de projeto, $f$ é a função a ser minimizada, o vetor de restrições de desigualdade $\mathbf{g}(\mathbf{b}, \mathbf{u}(\mathbf{b}))$ possui $m$ restrições, que devem ser atendidas para todos os $n_{t}$ instantes de tempo. Por fim, $\mathbf{b}_{l}$ e $\mathbf{b}_{u}$ são as restrições laterais para as variáveis do vetor b. Nesta dissertação, os efeitos de amortecimento estrutural não são considerados, de modo que a equação 
que rege a dinâmica no sistema pode ser simplificada como apresentado na formulação 4-1. Comumente em otimização estrutural, restrições de igualdade da forma $\mathbf{h}(\mathbf{b}, \mathbf{u}(\mathbf{b}))=0$ não são presentes, então este trabalho assume a formulação apresentada em 4-1 como a representação de um problema geral de otimização estrutural dinâmica.

\subsection{1}

\section{Abordagem Tradicional para Otimização Estrutural Dinâmica}

As equações desenvolvidas nos capítulos 2 e 3 para análise em elementos finitos e computação de sensibilidades foram utilizadas para desenvolver um código em MATLAB ${ }^{\circledR}$ e a otimização foi realizada pela função do pacote Optimization Toolbox fmincon, que resolve o problema formulado em 4-1. A função fmincon deve receber como parâmetros de entrada a função objetivo, o vetor de restrições, as derivadas da função objetivo e restrições com respeito às variáveis de projeto, o limites inferior e superior. No caso em que as derivadas não são fornecidas, estas são calculadas automaticamente e fornecidas por diferenças finitas, aumentando o número de avaliações da função objetivo e, por consequência, o custo computacional. A cada iteração de otimização é necessário realizar uma nova análise dinâmica, devido a atualizações das variáveis de projeto.

\section{2}

\section{Geração de Carregamentos Estáticos Equivalentes}

A principal idéia por trás do conceito de carregamento estático equivalente consiste em gerar carregamentos de natureza estática que apresentem o mesmo campo de respostas que o carregamento dinâmico original para todos os instantes de tempo [16]. Em uma análise estrutural estática, a equação que rege o comportamento do sistema é escrita como:

$$
\mathbf{K} \mathbf{x}=\mathbf{s}
$$

onde $\mathbf{x}$ é a resposta correspondente ao forçamento $\mathbf{s}$. Para que o vetor $\mathbf{s}$ e o vetor $\mathbf{F}(t)$ correspondente à análise dinâmica, Equação (2-1), apresentem a mesma resposta de deslocamentos, é necessário verificar que:

$$
\mathbf{f}^{e q}(t)=\mathbf{K u}(t)
$$

para todos os instantes $t$. Define-se através de Equação (4-3) o vetor de carregamento estático equivalente $\mathbf{f}^{e q}$. Os deslocamentos gerados por $\mathbf{f}^{e q}$ são os mesmos que o vetor $\mathbf{F}$ no instante $t$. A relação entre o carregamento dinâmico 
e o vetor ESL pode ser obtida [16] para o caso linear elástico por meio da Equação (2-1), substituindo nela a Equação (4-3), ou seja:

$$
\mathbf{f}^{e q}(t)=\mathbf{F}(t)-\mathbf{M} \ddot{\mathbf{u}}(t)-\mathbf{C} \dot{\mathbf{u}}(t)
$$

É importante ressaltar que a Equação (4-3) define um carregamento estático equivalente $\mathbf{f}^{e q}(t)=\mathbf{f}^{e q}(s)$, onde $s$ é um caso de carga no qual o carregamento estático $\mathbf{f}^{e q}$ gera um campo de deslocamentos igual ao gerado pela força $\mathbf{F}(t)$ num dado instante $t$ em particular. Existe uma relação direta entre o instante de tempo $t$ e o caso de carga $s$. Uma análise cujo tempo é dividido em $q$ instantes de tempo irá produzir a mesma quantidade $q$ de casos de carga, uma para cada tempo. Sendo assim, de modo a obter a mesma resposta de deslocamento utilizando o conceito de carregamentos estáticos equivalentes, a Equação (4-3) deve ser calculada para todos os instantes da análise dinâmica. Desse modo, um vetor de carregamentos externos para caso de carga associado à cada instante de tempo é gerado e, como consequência, ambos os carregamentos estático e dinâmico geram exatamente o mesmo campo de deslocamentos. A Figura (4.1) ilustra a transformação de um campo de respostas no domínio dinâmico em um campo de respostas estático. Neste novo domínio, a variável passa a ser o caso de carga $s$, onde para cada $s$ deste domínio existe um $t$ correspondente no domínio dinâmico. Outra interpretação importante a respeito da Equação (4-3) se dá ao fato de que os carregamentos são calculados simplesmente pela multiplicação da matriz de rigidez pelo vetor de deslocamentos obtido da análise dinâmica do problema original. Os vetores obtidos desse produto são aplicados na otimização como carregamentos externos em uma análise estática considerando múltiplos casos de carga. Uma consequência direta (Figura 4.2) da formação dos carregamentos estáticos serem gerados em todos os instantes de tempo é que nenhum dos vetores gerados possui elementos nulos, isto é, independente da disposição que o carregamento dinâmico é aplicado no problema original, durante a etapa de análise estática os carregamentos estáticos são aplicados em todos os nós da estrutura, e em todos os seus graus de liberdade. 
Capítulo 4. Otimização Estrutural e o Método do Carregamento Estático Equivalente
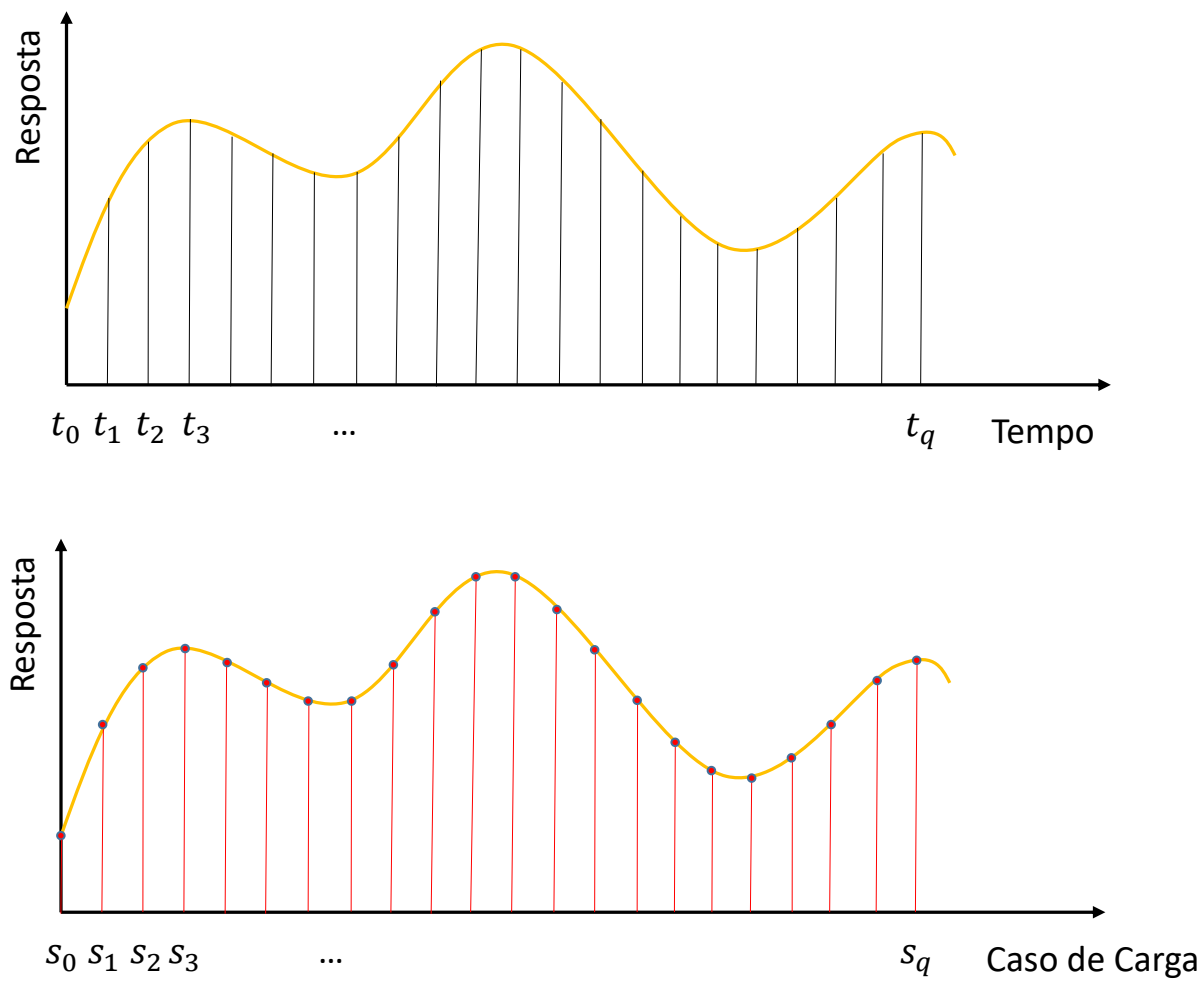

Figura 4.1: Transformação de carregamentos dinâmicos em equivalentes estáticos para vários casos de carga.
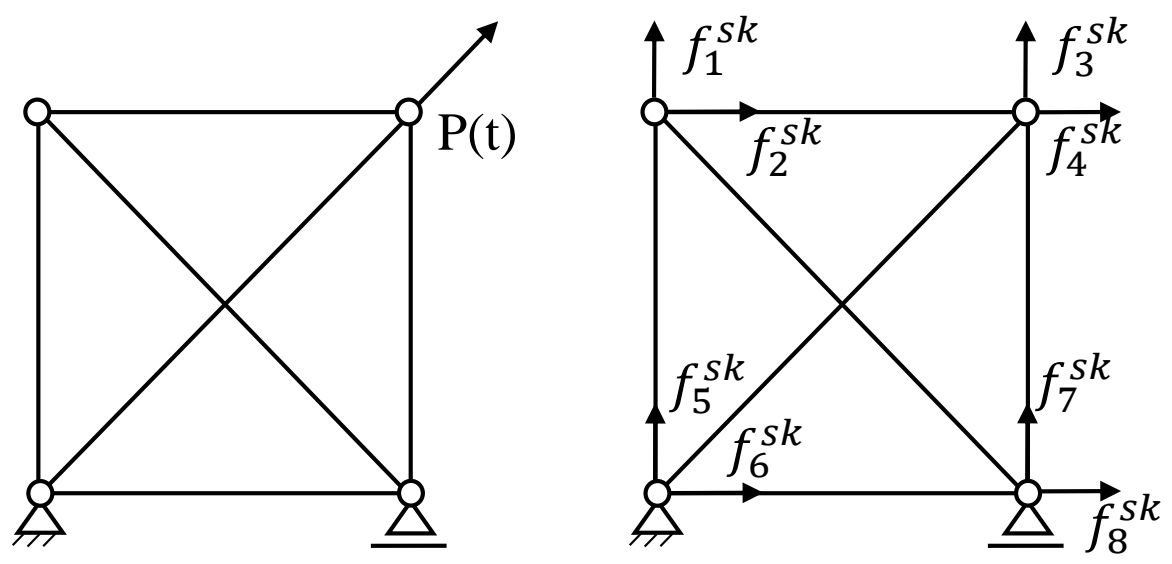

Figura 4.2: Caso de carga $s^{k}$ equivalente ao tempo $t$ 


\section{3}

\section{Otimização Sequencial via ESL}

O algoritmo para a otimização dinâmica utilizando o método do carregamento estático equivalente divide-se nas seguintes etapas: primeiramente, é definido um vetor inicial de variáveis de projeto e, a partir da discretização do sistema em elementos finitos, a equação do movimento é resolvida e as respostas dinâmicas dos deslocamentos nodais são obtidas. Em seguida, os carregamentos estáticos equivalentes são gerados por meio da multiplicação da matriz de rigidez pelo vetor de deslocamentos dinâmicos. Sendo assim, os vetores de ESL obtidos são interpretados como múltiplos casos de carga que produzem, para cada caso de carga, os mesmos deslocamentos que o carregamento dinâmico original em cada instante de tempo. Uma vez gerados os casos de carga, é feita a otimização estrutural estática considerando os múltiplos casos. Ao final da otimização, um novo conjunto de variáveis de projeto é gerado.

O critério de convergência para o método ESL consiste na definição de uma tolerância na qual a norma da diferença entre as soluções de duas iterações de otimização estrutural estática seguidas seja menor que a tolerância. Além disso, todas as restrições devem ser atendidas. Nesse caso, o processo é terminado e a solução ótima obtida na última otimização estrutural estática é também solução do problema original de otimização dinâmica. Caso o critério ou as restrições não sejam atendidos, o vetor de variáveis de projeto é atualizado e um novo ciclo é ininciado a partir da análise dinâmica. Na iteração seguinte, as variáveis iniciais são as mesmas que as obtidas na otimização do passo anterior. O processo continua iterativamente até a convergência ser verificada. A Figura (4.3) e o Algoritmo (1) apresentam um fluxograma e uma descrição mais detalhada do processo de otimização por meio do método ESL. 


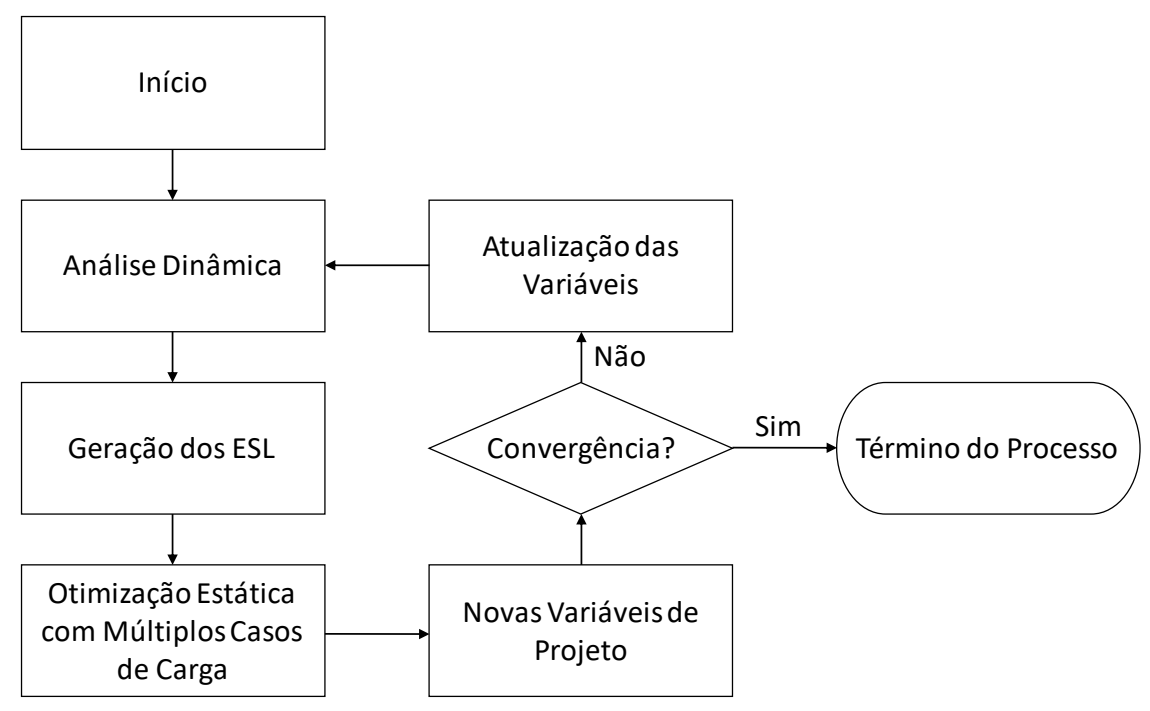

Figura 4.3: Fluxograma do processo de otimização com a aplicação dos carregamentos estáticos equivalentes.

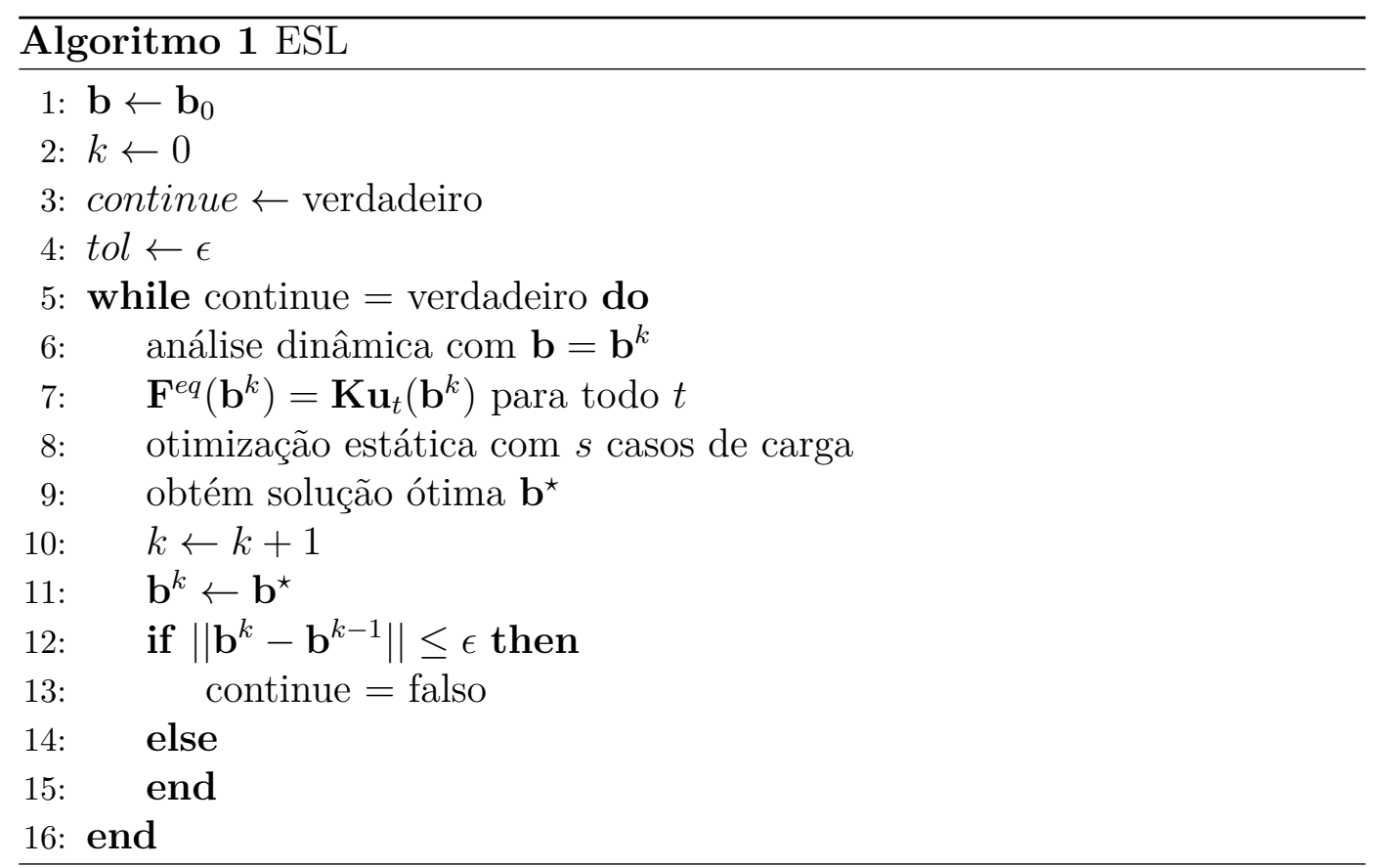

\section{4}

\section{Exemplos Numéricos}

Nesta seção são apresentados problemas clássicos de otimização envolvendo estruturas estruturas treliçadas submetidas a restrições dependentes do tempo que são solucionadas por meio do método do ESL. Para a validação do 
método empregado, os problemas também são resolvidos utilizando métodos de otimização dinâmica tradicional.

\subsection{1}

\section{Treliça de 5 Barras}

O primeio problema estudado, retirado de (Silva [34]), consiste em minimizar o peso de uma treliça de 5 barras, Figura (4.4), sujeita a uma carga dinâmica (Figura 4.5) aplicada na estrutura. As distâncias retratadas são medidas em polegadas (in). Restrições de tensão e deslocamento são consideradas no modelo. A treliça possui 5 nós e 5 elementos e os apoios limitam todos os graus de liberdade dos nós 1 e 4, e o grau de liberdade horizontal do nó 5 . O carregamento aplicado na treliça é de forma senoidal $P(t)=A \operatorname{sen}(\omega t)$ de amplitude $A$ igual a $20000 l b$ e frequência $\omega$ igual a $1 \mathrm{rad} / \mathrm{s}$. Foram utilizados $t_{i}=0 s, t_{f}=2 \mathrm{~s}$ e $d t=0.2 \mathrm{~s}$. Dessa forma, o método ESL gera 11 casos de carga, um para cada instante de tempo. Os valores do módulo de elasticidade e peso específico são, respectivamente, $E=10^{7} \mathrm{psi}$ e $\gamma=0.1 \mathrm{lb} / \mathrm{in}^{3}$.

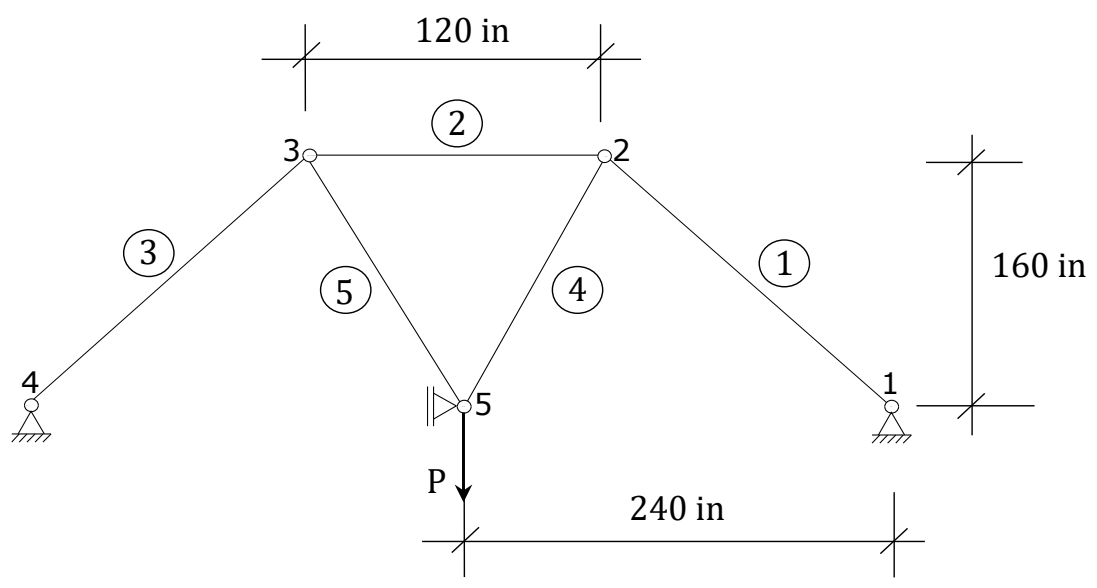

Figura 4.4: Treliça de 5 barras.

A Equação (4-5) apresenta a formulação do problema. As restrições de tensão e deslocamento são apresentadas, e dois casos são estudados:

- Caso 1: Restrição de tensão para todos os elementos;

- Caso 2: Restrição de tensão para todos os elementos e restrição de deslocamento para o nó 5.

O módulo da tensão axial em cada elemento, assim como o módulo do deslocamento vertical no nó 5 , devem ser menores ou iguais ao valores impostos na Equação (4-5). 
A rotina de entrada gerada para realizar a análise dinâmica no ANSYS é apresentada no Apêndice A. Após calcular a resposta do sistema dinâmico, os resultados são exportados para o módulo de otimização via ESL no MATLAB. Uma vez otida a solução ótima do subproblema linear estático, a rotina de entrada é atualizada e um novo ciclo se inicia. O processo continua até duas iterações consecutivas apresentarem o mesmo vetor de solução ótima.

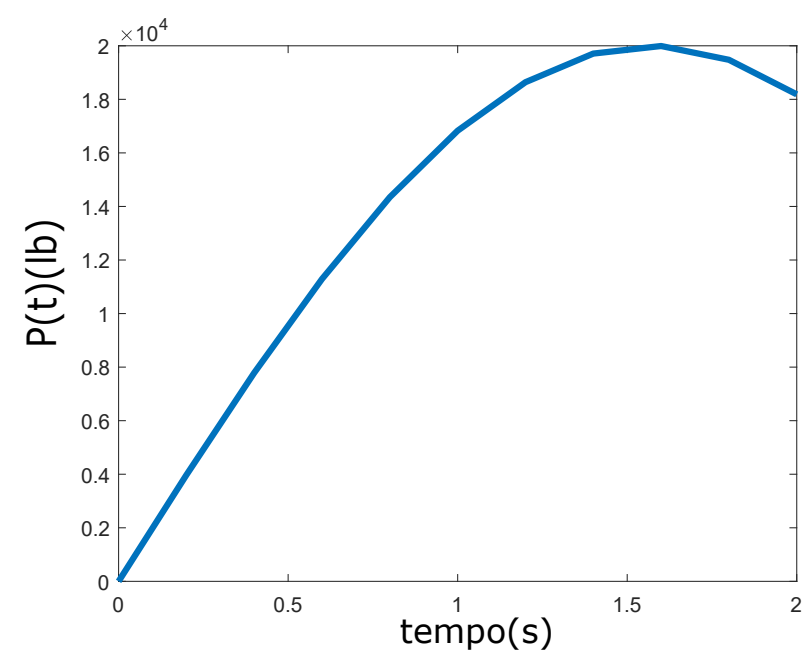

Figura 4.5: Carregamento $\mathrm{P}(\mathrm{t})$.

$$
\begin{array}{ll}
\min & \operatorname{peso}(\mathbf{b}) \\
\text { s.t. } & \left|\sigma_{i, t}\right|-20000 \text { psi } \leq 0, i=1, \ldots, 5 . \\
& \left|u_{5, y, t}\right|-1,2 \text { in } \leq 0 \\
& \mathbf{b}_{l} \leq \mathbf{b} \leq \mathbf{b}_{u} \\
& t=0 s, 0.2 s, \ldots, 2 \mathrm{~s}
\end{array}
$$

O limite inferior para todas as áreas é $b_{l}=0.1$, valor inicial é $b_{0}=1$ e o limite superior é igual a 10.

A Tabela (4.1) apresenta os resultados obtidos para a função objetivo da referência [34], a otimização utilizando o ESL e a validação com a otimização dinâmica para os 2 casos estudados na referência. O valores obtidos pelo método ESL e pela otimização sujeita a carregamentos dinâmicos são idênticos para o caso apenas com restrições de tensão e bastante próximo para o caso envolvendo restrições de deslocamento e tensão.

A Tabela (4.2) mostra o número de iterações da otimização via abordagem tradicional e via ESL, bem como a quantidade de otimizações estáticas requeridas pelo método ESL para convergir. Vale ressaltar que as iterações no 
caso ESL são a soma do número de iterações necessárias em cada ciclo de otimização sequencial estática, e por esse motivo o número é maior que no caso tradidional. O tempo necessário para a resolução do caso 2 foi $t_{\text {din }}=0.13 \mathrm{~s}$ para a implementação dinâmica e $t_{E S L}=0.76 \mathrm{~s}$ para o método ESL. A Tabela (4.3) mostra a solução ótima para o vetor de variáveis de projeto ao final de cada iteração do método ESL.

A Tabela (4.4) reúne os valores das áreas de seção transversal ao final do processo de otimização sujeito a restrições de tensão e deslocamento, caso 2 . O método ESL apresentou valores mais próximos à referência que a otimização tradicional.

Tabela 4.1: Comparação da função objetivo para a treliça de 5 barras.

\begin{tabular}{cccc} 
& \multicolumn{3}{c}{ Peso Otimizado $(l b)$} \\
\cline { 2 - 4 } & Referência [34] & ESL & Dinâmico \\
\hline Caso 1 & 63.58 & 64.51 & 64.51 \\
\hline Caso 2 & 67.28 & 67.93 & 67.88 \\
\hline
\end{tabular}

A Figura (4.6) mostra os valores da função objetivo que a função objetivo ao longo do processo de otimização até que a obtenção da solução ótima seja alcançada. A convergência do peso da treliça é mostrado para o método tradicional de otimização submetida a carregamentos dinâmicos e para o método ESL nas curvas em preto e colorido, respectivamente. Como o método ESL resolve diversos subproblemas de otimização sujeita a carregamentos estáticos, cada segmento no gráfico corresponde à uma dessas otimizações. Analisando o comportamento das duas curvas é possível ver que o método ESL, ao final do primeiro ciclo, já se aproxima rapidamente da solução ótima, necessitando dos demais ciclos para garantir satisfação do

Tabela 4.2: Número total de iterações em cada método e número de otimizações sequencais estáticas realizadas no método ESL.

Número de Iterações

Dinâmico ESL Otimizações Estáticas (ESL)

\begin{tabular}{llll} 
Caso 1 & 5 & 14 & 5 \\
\hline Caso 2 & 13 & 72 & 25 \\
\hline
\end{tabular}


Tabela 4.3: Solução ótima ao final de cada iteração do método ESL - Caso 1.

\begin{tabular}{c|ccccc} 
& \multicolumn{5}{|c}{ Solução Ótima - Caso 1 $\left(\mathrm{in}^{2}\right)$} \\
\hline Ciclo (ESL) & $\mathbf{A}_{\mathbf{1}}$ & $\mathbf{A}_{\mathbf{2}}$ & $\mathbf{A}_{\mathbf{3}}$ & $\mathbf{A}_{\mathbf{4}}$ & $\mathbf{A}_{\mathbf{5}}$ \\
\hline $\mathbf{0}$ & 1 & 1 & 1 & 1 & 1 \\
\hline $\mathbf{1}$ & 0.7714 & 0.7674 & 0.7714 & 5406 & 5406 \\
\hline $\mathbf{2}$ & 0.7685 & 0.7606 & 0.7685 & 0.5371 & 0.5371 \\
\hline $\mathbf{3}$ & 0.7686 & 0.7607 & 0.7686 & 0.5371 & 0.5371 \\
\hline $\mathbf{4}$ & 0.7686 & 0.7607 & 0.7686 & 0.5371 & 0.5371 \\
\hline
\end{tabular}

Tabela 4.4: Solução ótima do caso 2 - Comparação entre a referência [34], o método ESL e aborgadem tradicional de otimização com carregamentos dinâmicos.

\begin{tabular}{cccc}
\multicolumn{4}{c}{ Áreas Ótimas $\left(i n^{2}\right)$ - Caso 2 } \\
\hline Variável & Referência [34] & ESL & Dinâmico \\
\hline 1 & 0.8007 & 0.8093 & 0.7864 \\
\hline 2 & 0.8089 & 0.8037 & 0.8176 \\
\hline 3 & 0.8007 & 0.8093 & 0.7864 \\
\hline 4 & 0.5641 & 0.5649 & 0.5907 \\
\hline 5 & 0.5641 & 0.5649 & 0.5907 \\
\hline
\end{tabular}

critério de convergência. A Figura (4.7) aproxima-se dos últimos ciclos do método ESL. É interessante salientar que a convergência no método ESL não é monotônica, visto que ocorrem momentos onde o valor da função objetivo sobe, correspondentes a configurações das variáveis de projeto que violam as restrições do problema momentaneamente, porém o método consegue realizar a otimização e a solução ótima é obtida. 


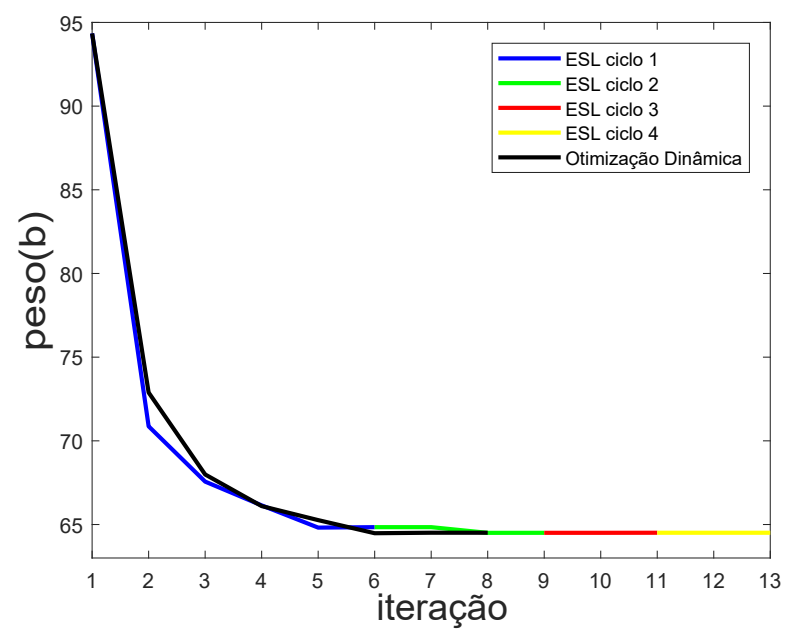

Figura 4.6: Convergência da função objetivo segundo otimização tradicional, em preto, e utilizando o método ESL, colorido, para a treliça de 5 barras - caso 1 .

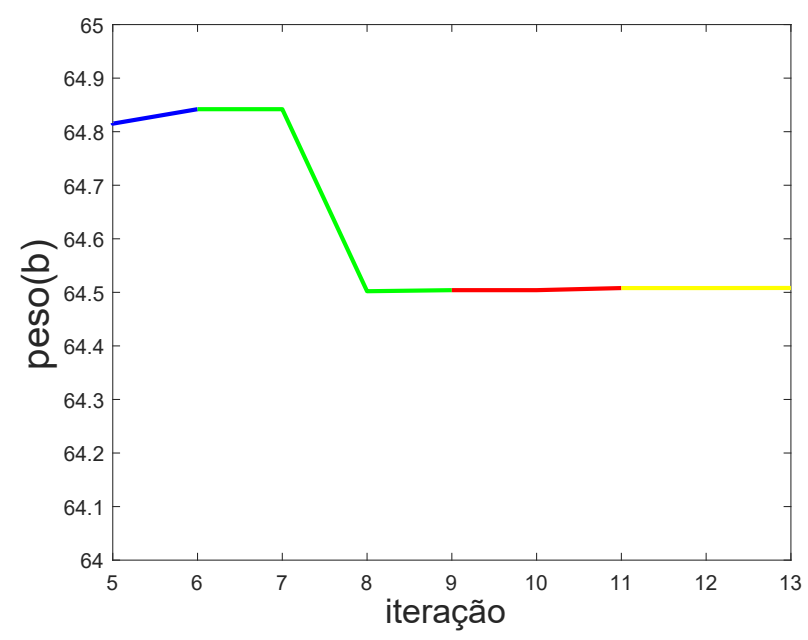

Figura 4.7: Ampliação da convergência nos últimos ciclos do método ESL para a treliça de 5 barras - caso 1.

\subsection{2}

\section{Treliça de 10 Barras}

O segundo exemplo, também retirado de Silva [34], trata da otimização do peso de uma treliça de 10 barras cujas variáveis de projeto são suas áreas de seção transversal (Figura 4.8). Novamente, as distâncias são medidas em polegadas. O carregamento aplicado é também um seno e sua expressão é $P(t)=100000 \operatorname{sen}(t)$. O carregamento concentrado é aplicado verticalmente para baixo em dois pontos na treliça. Os valores do módulo de elasticidade e peso específico são, respectivamente, $E=10^{7}$ psi e $\gamma=0.1 \mathrm{lb} / \mathrm{in}^{3}$ e $L=360 \mathrm{in}$. 
A análise foi feita até $t_{f}=2 \mathrm{~s}$, com passo de $d t=0.5 \mathrm{~s}$. A Tabela (4.5) apresenta os casos estudados utilizando a treliça de 10 barras. No primeiro e segundo casos, apenas retrições de tensão são impostas, enquanto que no terceiro caso, a treliça está submetida a retrições de tensão igual ao caso 1 em todos os elementos, e os nós de 1 a 4 apresentam retrições de deslocamento nos graus de liberdade verticais. O peso da estrutura para a configuração inicial de variáveis de projeto é de $4196.46 l b$ para os 3 casos, o limite infeior é $b_{l}=0.1 \mathrm{in}^{2}$ e superior $b_{u}=50 \mathrm{in}^{2}$.

$$
\begin{array}{ll}
\min & \operatorname{peso}(\mathbf{b}) \\
\text { s.t. } & \left|\sigma_{i, t}\right|-\bar{\sigma} \leq 0, i=1, \ldots, 10 . \\
& \left|u_{j, y, t}\right|-\bar{u} \leq 0,, j=1, \ldots, 4 . \\
& \mathbf{b}_{l} \leq \mathbf{b} \leq \mathbf{b}_{u} \\
& t=t_{i}, \ldots, t_{f}
\end{array}
$$

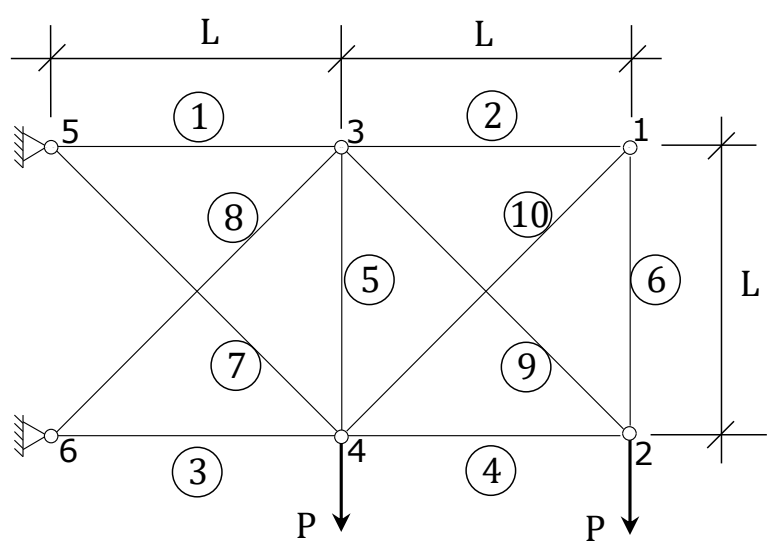

Figura 4.8: Treliça de 10 barras.

A Tabela (4.6) mostra os resultados obtidos para o peso ótimo da estrutura nos casos 1 a 3 .

É possível ver que o método do ESL obteve resultados melhores que os obtidos na referência para todos os casos, e a validação feita por otimização dinâmica convencional mostra a consistência do método para este problema. As Figuras (4.9) e (4.10) apresentam as respostas estruturais de deslocamento e tensão da estrutura otimizada para os casos 1 e 3 , respectivamente. Para melhor ilustrar a diferença dos casos, os valores limites de deslocamento impostos no caso 3 também foram plotados no gráfico do caso 1, de modo que, como 
Tabela 4.5: Restrições envolvidas nos casos 1, 2 e 3 para a treliça de 10 barras.

\begin{tabular}{lcc} 
& Restrição de Tensão & Restrição de Deslocamento \\
\cline { 2 - 3 } Caso 1 & $\bar{\sigma}=25000$ psi & Não \\
\hline Caso 2 & $\bar{\sigma}=30000$ psi & Não \\
\hline Caso 3 & $\bar{\sigma}=25000$ psi & $\bar{u}=2$ in \\
\hline
\end{tabular}

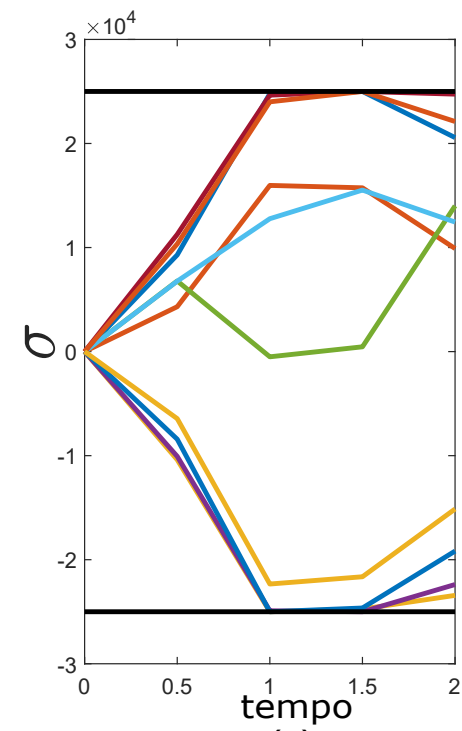

(a)

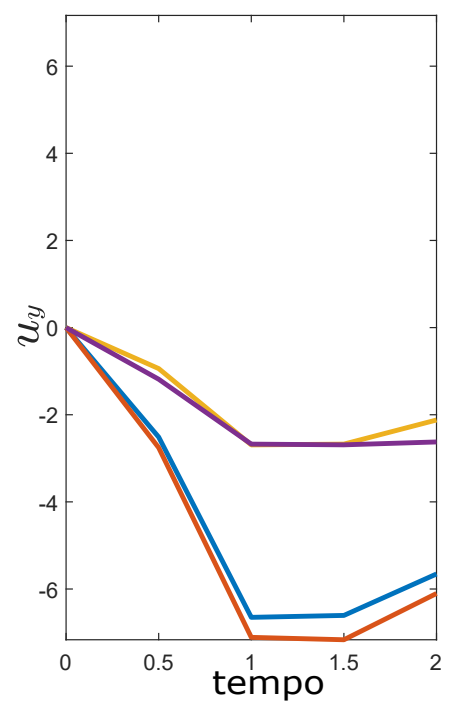

(b)

Figura 4.9: Treliça de 10 barras, caso 1. (a) Tensões admissíveis em preto sendo respeitadas durante todo o intervalo de simulação; (b) Deslocamentos verticais não estão sujeitos a restrições.

Tabela 4.6: Função objetivo - Treliça de 10 barras.

\begin{tabular}{lccc} 
& \multicolumn{3}{r}{ Peso Otimizado (lb) } \\
\cline { 2 - 4 } & Referência [34] & ESL & Dinâmico \\
\cline { 2 - 4 } Caso 1 & 1609.18 & 1563.51 & 1563.51 \\
\hline Caso 2 & 1342.55 & 1304.84 & 1304.84 \\
\hline Caso 3 & 5138.66 & 5060.42 & 5060.43
\end{tabular}

esperado, os deslocamentos nos nós são maiores. As Figuras (4.11) e (4.12) apresentam o histórico de convergência da função objetivo ao longo de cada ciclo do método ESL desde o vetor inicial de variáveis de projeto até a solução 


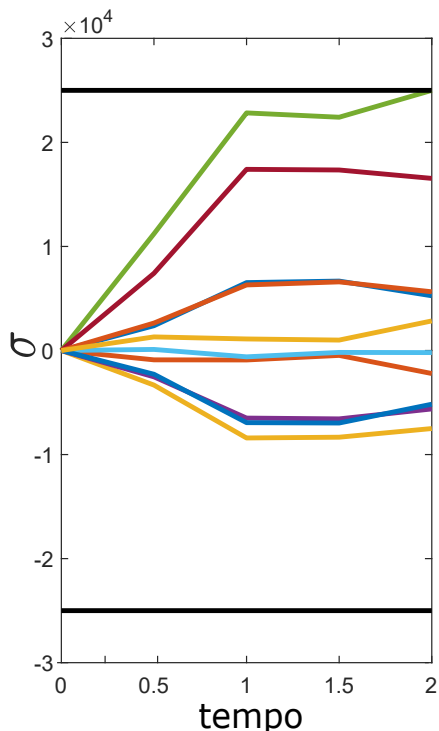

(a)

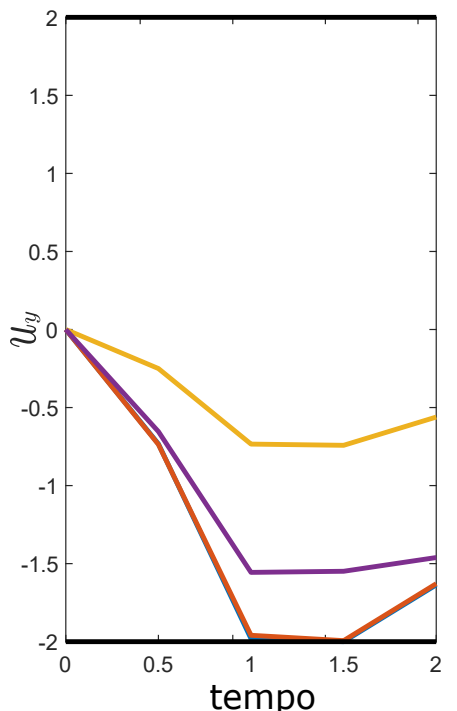

(b)

Figura 4.10: Treliça de 10 barras, caso 3. (a) Tensões respeitam as restrições estabelecidas; (b) Deslocamentos também atendem os limites admissíveis de deslocamento, em preto, em toda a simulação.

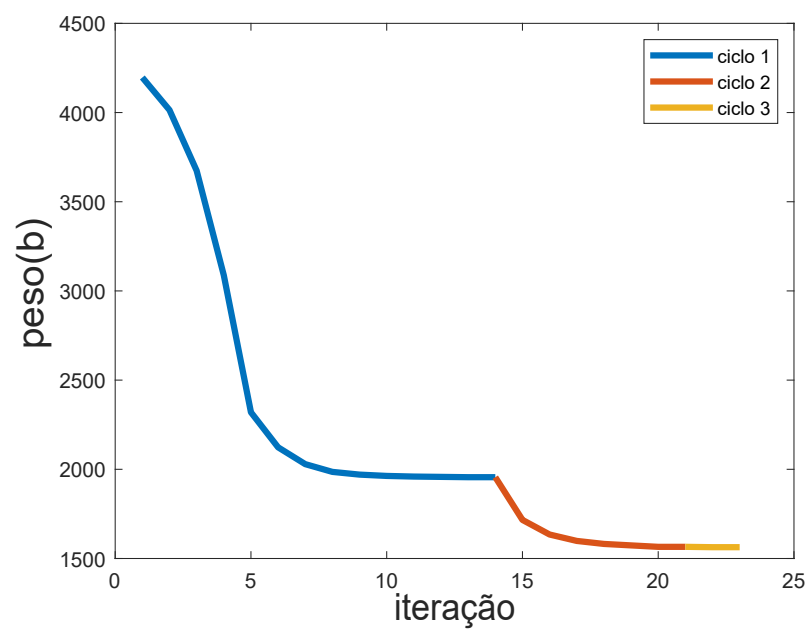

Figura 4.11: Treliça de 10 barras, caso 1. Convergência da função objetivo do longo de cada ciclo do método ESL.

ótima obtida.

As Tabelas (4.8) e (4.9) apresentam a atualização das variáveis de projeto ao longo de cada ciclo do método ESL, ou seja, de cada otimização sequencial estática. Todas as áreas inicialmente possuem valor $A_{0}=10 \mathrm{in}^{2}$ no caso 1 , e $30 i n^{2}$ no caso 3. Para o caso 1, 4 ciclos do método ESL foram necessários enquanto que para o caso 3 foram realizados 5 ciclos. É observado para os dois casos que as variáveis que assumem os valores delimitados pelo limite inferior 


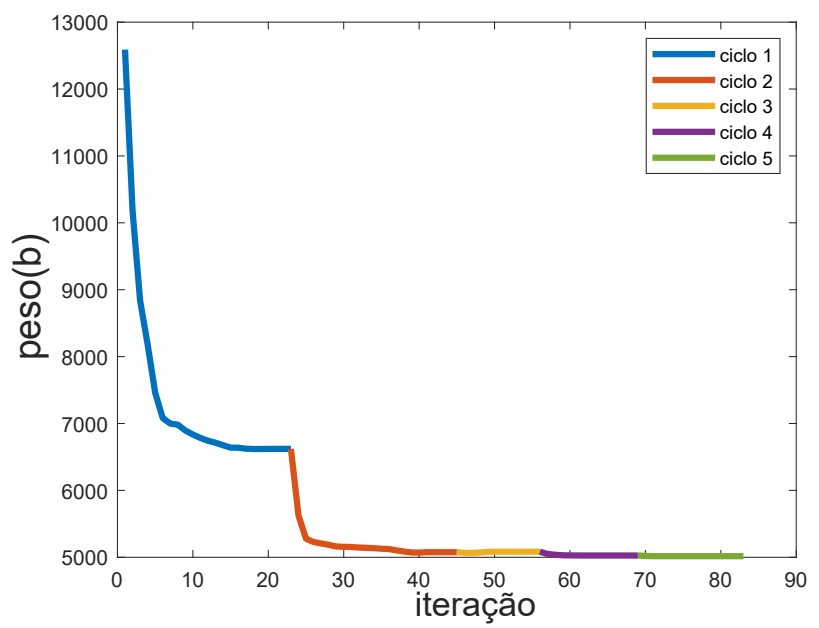

Figura 4.12: Treliça de 10 barras, caso 3. Convergência da função objetivo do longo de cada ciclo do método ESL.

Tabela 4.7: Iterações e número de ciclos do método ESL - 10 barras.

\begin{tabular}{cccc} 
& \multicolumn{4}{c}{ Número de Iterações } \\
\cline { 2 - 4 } Caso 1 & 10 & 23 & 3 \\
\hline Dinâmico & ESL & Ciclos do método ESL \\
\hline Caso 2 & 10 & 23 & 3 \\
\hline Caso 3 & 45 & 83 & 5 \\
\hline
\end{tabular}

do problema convergem rapidamente para os valores mínimos, como esperado algumas das barras mais à direita da treliça. Já as variáveis que convergem para valores diferentes de $b_{l}$ apresentaram convergência com um número maior de iterações, porém os valores obtidos para cada variável nas últimas linhas já são suficientemente próximos para afirmar que a solução ótima foi obtida. 
Capítulo 4. Otimização Estrutural e o Método do Carregamento Estático

Equivalente

Tabela 4.8: Convergência das variáveis de projeto ao longo das otimizações sequenciais no método ESL para o caso 1.

\section{Ciclo do método ESL}

\begin{tabular}{c|cccc}
\hline $\mathbf{A}\left(i n^{2}\right)$ & $\mathbf{0}$ & $\mathbf{1}$ & $\mathbf{2}$ & $\mathbf{3}$ \\
\hline $\mathbf{A}_{\mathbf{1}}$ & 10 & 9.921 & 7.906 & 7.903 \\
$\mathbf{A}_{\mathbf{2}}$ & 10 & 0.560 & 0.1 & 0.1 \\
$\mathbf{A}_{\mathbf{3}}$ & 10 & 9.857 & 7.784 & 7.759 \\
$\mathbf{A}_{\mathbf{4}}$ & 10 & 4.482 & 3.832 & 3.828 \\
$\mathbf{A}_{\mathbf{5}}$ & 10 & 0.1 & 0.1 & 0.1 \\
$\mathbf{A}_{\mathbf{6}}$ & 10 & 0.373 & 0.1 & 0.1 \\
$\mathbf{A}_{\mathbf{7}}$ & 10 & 6.794 & 5.467 & 5.445 \\
$\mathbf{A}_{\mathbf{8}}$ & 10 & 6.825 & 5.689 & 5.695 \\
$\mathbf{A}_{\mathbf{9}}$ & 10 & 6.246 & 5.473 & 5.472 \\
$\mathbf{A}_{\mathbf{1 0}}$ & 10 & 0.661 & 0.1 & 0.1 \\
\hline
\end{tabular}

Tabela 4.9: Convergência das variáveis de projeto ao longo das otimizações sequenciais no método ESL para o caso 3.

Ciclo do método ESL

\begin{tabular}{c|cccccc}
\hline $\mathbf{A}\left(i n^{2}\right)$ & $\mathbf{0}$ & $\mathbf{1}$ & $\mathbf{2}$ & $\mathbf{3}$ & $\mathbf{4}$ & $\mathbf{5}$ \\
\hline $\mathbf{A}_{\mathbf{1}}$ & 30 & 37.642 & 30.428 & 31.047 & 30.809 & 30.766 \\
$\mathbf{A}_{\mathbf{2}}$ & 30 & 3.583 & 0.1 & 0.1 & 0.1 & 0.1 \\
$\mathbf{A}_{\mathbf{3}}$ & 30 & 32.256 & 22.820 & 23.040 & 22.931 & 22.911 \\
$\mathbf{A}_{\mathbf{4}}$ & 30 & 16.377 & 15.248 & 15.285 & 15.075 & 15.043 \\
$\mathbf{A}_{\mathbf{5}}$ & 30 & 0.1 & 0.1 & 0.1 & 0.1 & 0.1 \\
$\mathbf{A}_{\mathbf{6}}$ & 30 & 0.1 & 1.972 & 0.585 & 0.433 & 0.419 \\
$\mathbf{A}_{\mathbf{7}}$ & 30 & 14.874 & 7.483 & 7.602 & 7.554 & 7.546 \\
$\mathbf{A}_{\mathbf{8}}$ & 30 & 24.065 & 21.399 & 21.610 & 21.404 & 21.367 \\
$\mathbf{A}_{\mathbf{9}}$ & 30 & 22.992 & 21.312 & 21.676 & 21.391 & 21.349 \\
$\mathbf{A}_{\mathbf{1 0}}$ & 30 & 4.628 & 0.1 & 0.1 & 0.1 & 0.1 \\
\hline
\end{tabular}

\subsection{3}

\section{Treliça de 20 Barras}

A treliça está submetida a um carregamento vertical para baixo, de natureza senoidal que vale $P(t)=100000 \sin (t)$. O módulo de Young e a densidade valem, respectivamente, $E=10^{7} \mathrm{psi}$ e $\gamma=0.1 \mathrm{lb} / \mathrm{in}^{3}$ e $L=360 \mathrm{in}$. 


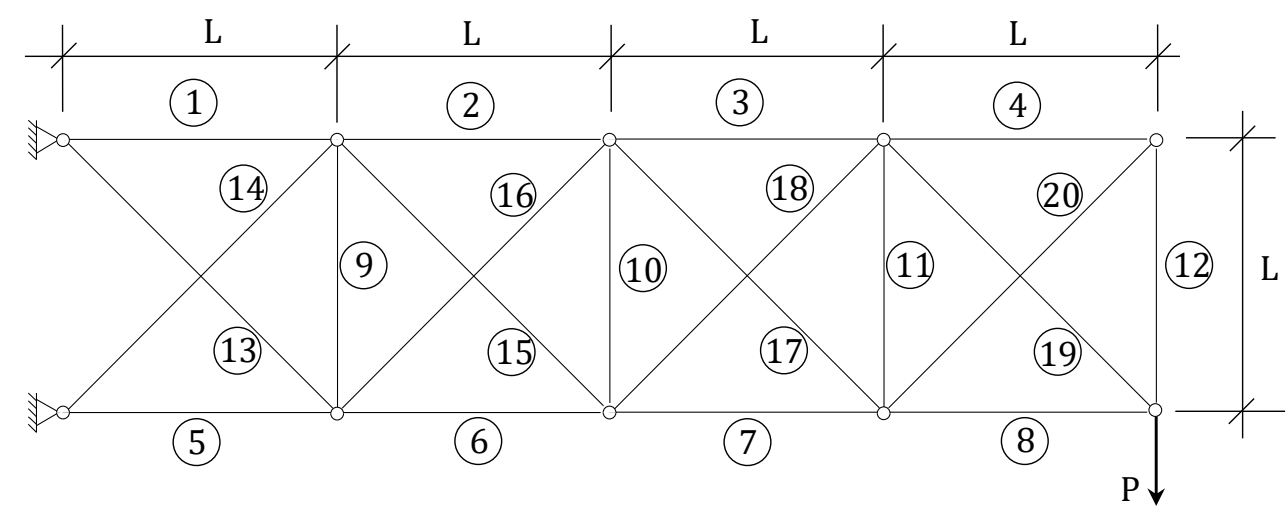

Figura 4.13: Treliça de 20 barras.

A análise foi feita até $t_{f}=10 \mathrm{~s}$, com passo de $d t=0.2 \mathrm{~s}$ A formulação do problema de otimização é apresentado a seguir:

$$
\begin{array}{ll}
\min & \operatorname{peso}(\mathbf{b}) \\
\text { s.t. } & \left|\sigma_{i, t}\right|-25000 \text { psi } \leq 0, i=1, \ldots, 20 . \\
& \mathbf{b}_{l} \leq \mathbf{b} \leq \mathbf{b}_{u} \\
& t=t_{i}, \ldots, t_{f}
\end{array}
$$

onde as variáveis de projeto são as áreas de seção transversal de cada barra, os limites inferior e superior para as barras valem $b_{l}=0,001 \mathrm{in}^{2}$ e $b_{u}=50 \mathrm{in}^{2}$, o valor inicial das variáveis de projeto é $b_{0}=30 i n^{2}$ e a tensão axial em todos os elementos deve ser menor que a tensão admissível definida na formulação.

A Tabela (4.10) Mostra os resultados obtidos para a otimização da treliça de 20 barras pela abordagem tradicional utilizando carregamentos dinâmicos e o método ESL. Os resultados foram bastante próximos. Como esperado, o método tradicional precisou de um número menor de iterações que o ESL.

Tabela 4.10: Função objetivo, iterações e número de ciclos do método ESL para a treliça de 20 barras.

Peso Otimizado (lb) Iterações Ciclos ESL

\begin{tabular}{llll}
\hline Dinâmico & 4958.18 & 36 & - \\
\hline ESL & 4954.43 & 62 & 8 \\
\hline
\end{tabular}




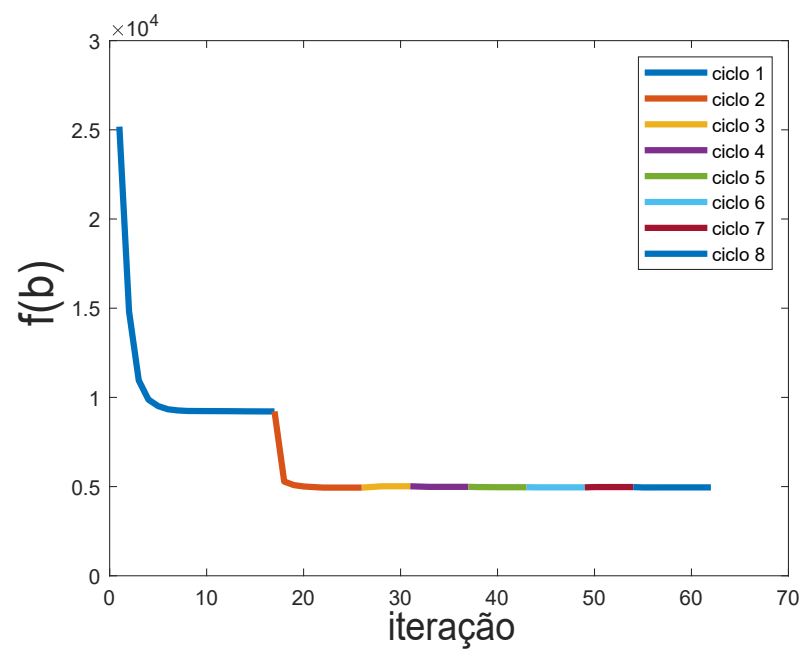

Figura 4.14: Convergência da função objetivo ao longo de cada ciclo do método ESL utilizando a integração Ansys - Matlab para a treliça de 20 barras.
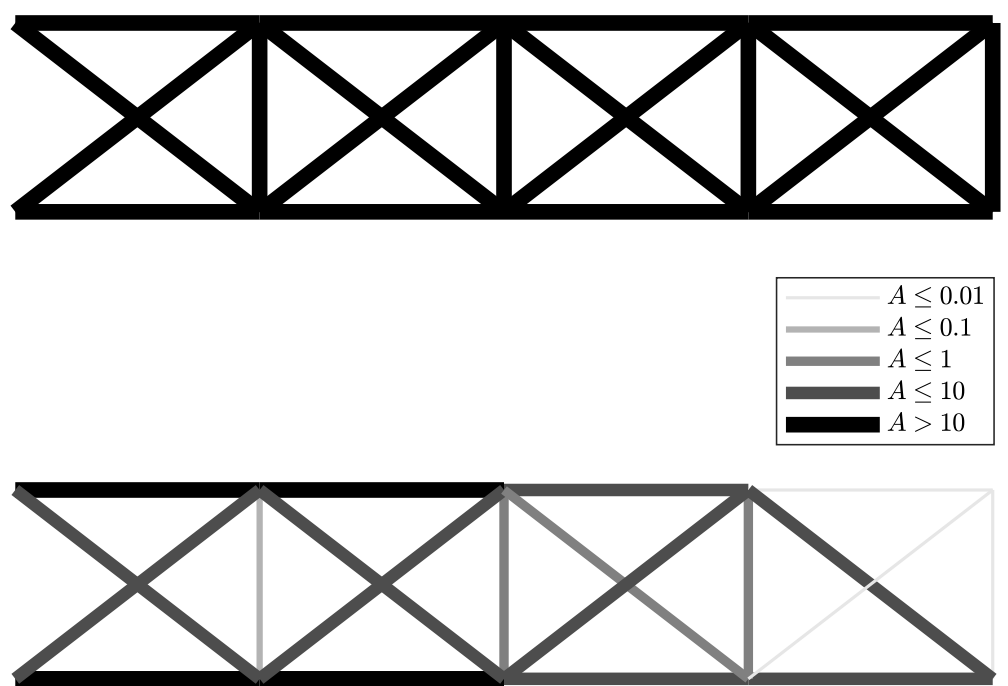

Figura 4.15: Configuração inicial e otimizada pelo método ESL -Treliça de 20 barras.

A Figura (4.14) mostra a convergência da função objetivo ao longo dos ciclos de otimização estática ocorrentes no método ESL. Como apresentado na legenda da figura, foram necessárias 8 iterações do método ESL para se alcançar convergência e obter a solução ótima. A Figura (4.15) ilustra a 
configuração inicial e otimizada da treliça, no que se diz respeito ao valor de cada área de seção reta da treliça. A fim de se ilustrar a diferença nos valores finais obtidos, foi aplicada uma escala na qual as tonalidades mais escuras e barras mais grossas foram atribuídas à areas maiores enquanto que tonalidades claras com barras de espessura mais fina indicam valores menores obtidos. A variação foi aplicada a cada ordem de grandeza, de modo que o valor mais escuro corresponde a áreas maiores ou iguais a $10 \mathrm{in}^{2}$ e o mais claro para áreas menores que $0.01 \mathrm{in}^{2}$, sendo assim apresentadas 5 faixas. 


\section{5 \\ Conclusões}

Nesta dissertação, o método do carregamento estático equivalente (ESL) foi utilizado como alternativa para a otimização de estruturas de treliça submetidas a carregamentos dinâmicos com restrições de deslocamento e tensão. Uma revisão bibliográfica sobre técnicas tradicionais em otimização estrutural submetida a carregamentos dependentes do tempo e do método do carregamento estático equivalente foi feita. A revisão da teoria necessária para a implementação de um algoritmo de otimização foi realizada, incluindo o método de elementos finitos para a modelagem da equação da dinâmica, o método de Newmark para a integração da equação diferencial no tempo e o cálculo das sensibilidades para o fornecimento analítico das derivadas da função objetivo e restrições com respeito às variáveis de projeto. O método ESL foi desenvolvido e sua implementação em um problema de otimização sujeito a carregamentos dinâmicos foi esquematizada. Uma interface utilizando o programa Ansys foi feita de modo que a análise em elementos finitos pudesse ser feita separadamente da rotina em Matlab para otimização via ESL.

Exemplos clássicos de treliças sujeitas a restrições dinâmicas de deslocamento e tensão foram resolvidos pelo método ESL e foram verificados com uma implementação tradicional de otimização estrutural com carregamentos dinâmicos. O método ESL apresentou resultados consistentes com os da referência estudada, e em alguns casos obteve valores menores para a função objetivo.

O número total de iterações requeridas pelo método ESL foi consistentemente maior quando comparado com a rotina de otimização tradicional. Este resultado era esperado, visto que o método resolve o problema original por meio da solução de uma sequência de subproblemas de otimização linear estática. Portanto, devido às múltiplas otimizações conduzidas, o número total de iterações é esperadamente maior. Visto que o custo da otimização estática é menor que o de uma otimização com restrições dinâmicas, o método ESL se torna viável, principalmente com a análise em elementos finitos sendo realizada por um programa robusto dedicado a essa tarefa, como o Ansys. 


\section{1}

\section{Trabalhos Futuros}

Nesta dissertação, estruturas de treliça foram estudadas sob restrições dinâmicas de tensão e deslocamento. Outros tipos de restrição também são de interesse acadêmico e prático, como a faixa permitida de frequências que podem aparecer na vibração da estrutura. Em uma análise dinâmica, é importante ter um controle sobre a faixa de frequências predominantes na estrutura, a fim de evitar operação em uma região próxima à de ressonância. Além disso, outros tipos de elementos finitos, como o de barra, para estruturas de viga e pórtico, ou até mesmo uma abordagem contínua podem ser estudados.

Esta dissertação teve como foco estudar estruturas que apresentam comportamento linear, de modo que a pesquisa segue aberta para o estudo de problemas cuja natureza apresente não linearidades, podendo ser geométrica, de material ou devido à mudança na fronteira do problema (problemas de contato).

A técnica envolvendo a substituição de carregamentos dinâmicos por carregamentos equivalentes que produzem a mesma resposta no sistema pode ser aplicada em outros problemas, por exemplo otimização topológica. Estudos recentes ainda começam a se aventurar nesse campo [22]. Visto que otimização topológica com carregamentos dinâmicos ainda é um campo com vasto horizonte a se explorar, a utilização do método ESL traz uma abordagem bastante ineressante ao problema. 


\section{6}

\section{Referências bibliográficas}

[1] Garret N Vanderplaats. Structural optimization for statics, dynamics and beyond. Journal of the Brazilian Society of Mechanical Sciences and Engineering, 28(3):316-322, 2006.

[2] Raphael T. Haftka and Zafer Gürdal. Elements of structural optimization, volume 11. Springer Science \& Business Media, 2012.

[3] RL Fox and MP Kapoor. Structural optimization in the dynamics response regime-a computational approach. AIAA Journal, 8(10):1798-1804, 1970.

[4] Gyung-Jin Park. Technical overview of the equivalent static loads method for non-linear static response structural optimization. Structural and Multidisciplinary Optimization, 43(3):319-337, 2011.

[5] A. G. M. Michell. The limits of economy of material in frame-structures. The London, Edinburgh, and Dublin Philosophical Magazine and Journal of Science, 8(47):589-597, 1904.

[6] Jacques Heyman. Plastic design of beams and plane frames for minimum material consumption. Quarterly of Applied Mathematics, 8(4):373-381, 1951.

[7] Lucien A Schmit. Structural design by systematic synthesis. In Proc. of Second Conference on Electronic Computation ASCE, New York, pages 105122, 1960.

[8] GN Vanderplaats. Structural design optimization status and direction. Journal of Aircraft, 36(1):11-20, 1999.

[9] Lucien André Schmit and B Farshi. Some approximation concepts for structural synthesis. AIAA journal, 12(5):692-699, 1974.

[10] J. F. M. Barthelemy and R. T. Haftka. Approximation concepts for optimum structural design - a review. Structural optimization, 5(3):129-144, Sep 1993.

[11] Byung-Soo Kang, Gyung-Jin Park, and Jasbir S Arora. A review of optimization of structures subjected to transient loads. Structural and Multidisciplinary Optimization, 31(2):81-95, 2006. 
[12] T-T Feng, JS Arora, and EJ Haug. Optimal structural design under dynamic loads. International Journal for Numerical Methods in Engineering, 11(1):3952, 1977.

[13] BS Kang, WS Choi, and GJ Park. Structural optimization under equivalent static loads transformed from dynamic loads based on displacement. Computers \& Structures, 79(2):145-154, 2001.

[14] WS Choi and GJ Park. Transformation of dynamic loads into equivalent static loads based on modal analysis. International Journal for Numerical Methods in Engineering, 46(1):29-43, 1999.

[15] U Choe, Sin-Cheon Gang, Min-Jae Sin, Gyeong-Jin Park, et al. Transformation of a dynamic load into an equivalent static load and shape optimization of the road arm in self-propelled howitzer. Transactions of the Korean Society of Mechanical Engineers A, 20(12):3767-3781, 1996.

[16] Woo-Seok Choi and Gyung-Jin Park. Structural optimization using equivalent static loads at all time intervals. Computer Methods in Applied Mechanics and Engineering, 191(19-20):2105-2122, 2002.

[17] GJ Park and BS Kang. Validation of a structural optimization algorithm transforming dynamic loads into equivalent static loads. Journal of optimization theory and applications, 118(1):191-200, 2003.

[18] Woo-Seok Choi, KB Park, and GJ Park. Calculation of equivalent static loads and its application. Nuclear engineering and design, 235(22):23372348, 2005.

[19] Moon-Kyun Shin, Ki-Jong Park, and Gyung-Jin Park. Optimization of structures with nonlinear behavior using equivalent loads. Computer Methods in Applied Mechanics and Engineering, 196(4-6):1154-1167, 2007.

[20] Yong-II Kim and Gyung-Jin Park. Nonlinear dynamic response structural optimization using equivalent static loads. Computer Methods in Applied Mechanics and Engineering, 199(9-12):660-676, 2010.

[21] HH Jang, HA Lee, JY Lee, and GJ Park. Dynamic response topology optimization in the time domain using equivalent static loads. AlAA journal, 50(1):226-234, 2012.

[22] Hyun-Ah Lee and Gyung-Jin Park. Nonlinear dynamic response topology optimization using the equivalent static loads method. Computer Methods in Applied Mechanics and Engineering, 283:956-970, 2015. 
[23] Klaus-Jürgen Bathe. Finite element procedures. Klaus-Jurgen Bathe, 2006.

[24] William Weaver Jr and Paul R Johnston. Structural dynamics by finite elements. Prentice-Hall Englewood Cliffs (NJ), 1987.

[25] Anil K Chopra. Dynamics of structures: Theory and applications. Prenticehall, 2001.

[26] Nathan M Newmark. A method of computation for structural dynamics. Journal of the engineering mechanics division, 85(3):67-94, 1959.

[27] Robert D Cook, David S Malkus, Michael E Plesha, and Robert J Witt. Concepts and applications of finite element analysis, volume 4. Wiley New York, 1974.

[28] Sundaramoorthy Rajasekaran. Structural dynamics of earthquake engineering: theory and application using MATHEMATICA and MATLAB. Elsevier, 2009.

[29] Jasbir Arora. Introduction to optimum design. Elsevier, 2004.

[30] Randall J LeVeque. Finite difference methods for ordinary and partial differential equations: steady-state and time-dependent problems, volume 98. Siam, 2007.

[31] Kyung K Choi and Nam-Ho Kim. Structural sensitivity analysis and optimization 1: linear systems. Springer Science \& Business Media, 2005.

[32] KK Choi and NH Kim. Structural sensitivity analysis and optimization 2: Non-linear systems and applications. 2005.

[33] Howard M. Adelman and Raphael Haftka. Sensitivity analysis of discrete structural systems. 24, 061986.

[34] Silva R A. Otimização estrutural sujeita a restrições dinâmicas. Master's thesis, Universidade Federal do Rio de Janeiro, 1992.

proceedings, artigo de congresso article, deve ser artigo de revista, confirmar!!! 
A

\section{Rotina de Análise em Elementos Finitos - Ansys}

/TITLE, Ansys/Matlab integration for static response

/FILNAM, Trans_Linear_Analysis

/CWD , C: \Users \rbian\Desktop \ESLcomANSYS\5barras \output

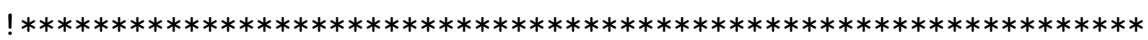

!PREPROCESSOR (input parameters, element type, temperature, ...)

! $* * * * * * * * * * * * * * * * * * * * * * * * * * * * * * * * * * * * * * * * * * * * * * * * * * * * * * * * * * * * * * * * *$

/PREP7

! Dimensions :

$E=10000000.000000$ ! Young's Modulus

rho $=0.100000 !$ Mass density

!Element Type:

ET , 1, LINK180

MPTEMP , 1,0

$\mathrm{MP}, \mathrm{EX}, 1, \mathrm{E}$

MP , PRXY , $1, \mathrm{nu}$

MP , DENS , 1 , rho

!Nodes definition:

$\mathrm{N}, 1,240.000000,0.000000,0$

$\mathrm{N}, 2,60.000000,160.000000,0$

$\mathrm{N}, 3,-60.000000,160.000000,0$

$\mathrm{N}, 4,-240.000000,0.000000,0$

$\mathrm{N}, 5,0.000000,0.000000,0$

$\mathrm{A} 1=0.807983$

!Element 1:

SECTYPE , 1, LINK

! defines the cross section type

SECDATA, A1

SECNUM , 1

E,1,2 ! element

$\mathrm{A} 2=0.802542$

!Element 2:

SECTYPE, 2 , LINK

! defines the cross section type

SECDATA, A2 
SECNUM , 2

E,2,3 ! element

$\mathrm{A} 3=0.807964$

!Element 3:

SECTYPE, 3, LINK

SECDATA , A3

! defines the cross section type

SECNUM , 3

E,4,3 ! element

$\mathrm{A} 4=0.564498$

!Element 4:

SECTYPE, 4 , LINK

! defines the cross section type

SECDATA , A4

SECNUM , 4

E,5,2 ! element

$\mathrm{A} 5=0.564494$

!Element 5:

SECTYPE, 5 , LINK

! defines the cross section type

SECDATA , A5

SECNUM, 5

E,5,3 ! element

!Degrees of freedom:

D, 1 , ALL

D , 4, ALL

D, 5 , UX

ALLSEL

FINISH

! $* * * * * * * * * * * * * * * * * * * * * * * * * * * * * * * * * * * * * * * * * * * * * * * * * * * * * * * * * * * * * * * * * * * * * * * * *$

! SOLUTION

! $* * * * * * * * * * * * * * * * * * * * * * * * * * * * * * * * * * * * * * * * * * * * * * * * * * * * * * * * * * * * * * * * * * * * * *$

/SOLU

ANTYPE, 4

! transient analysis

NLGEOM , OFF

! non-linear analysis: OFF

TRNOPT , FULL , , , , , NMK

! specifies transient analysis options: FULL

LUMPM, 0

SOLCONTROL, ON

TIMINT, ON

! turns on transient effects

TINTP, 0.005

! defines transient integration parameters

! Load:

*DIM, Force, TABLE , 11, 1, 1, , , TIME 


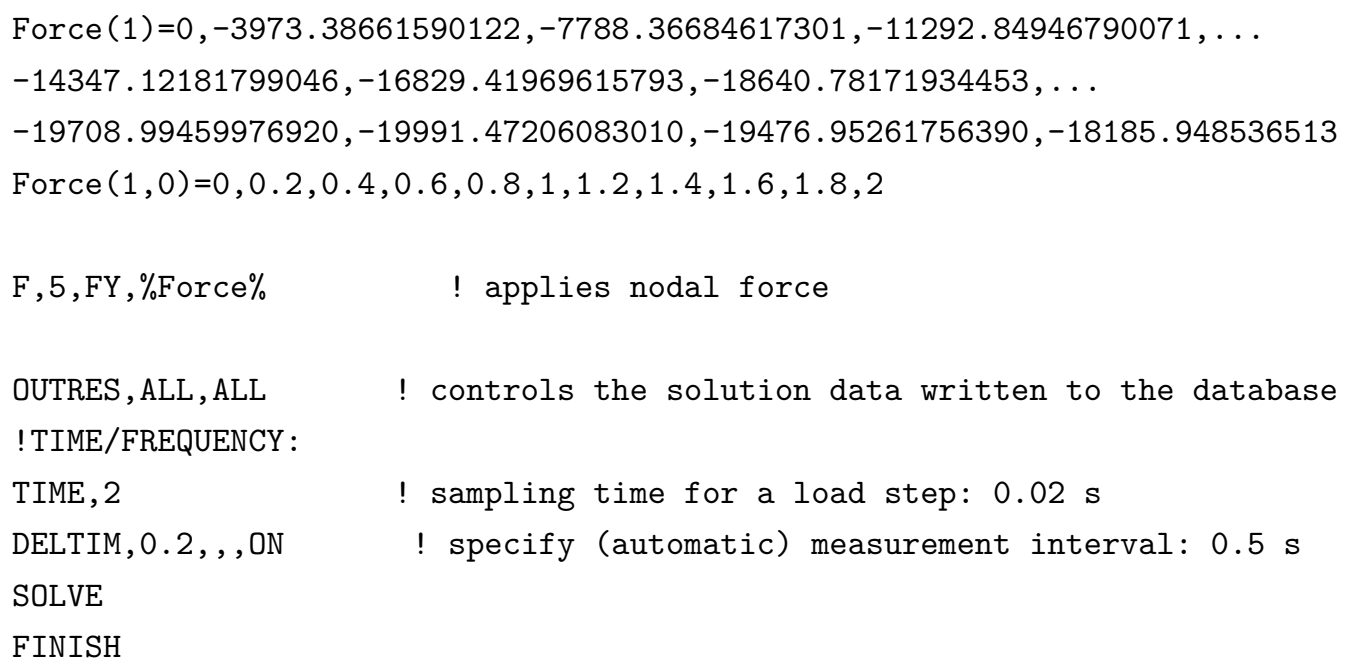
nd $=0$

*DO , i , 1, NumNode, 1

nd $=$ nd +1

tagNode1 $=2 * i$

tagNode $2=2 * i+1$

NSOL , tagNode $1, i, U, X$

STORE, MERGE

*GET , size, VARI , , NSETS

NSOL, tagNode $2, i, U, Y$

*DIM, UX_node $\%$ nd $\%$, array, size

*DIM, UY_node $\%$ nd $\%$, array, size

VGET,UX_node $\%$ nd $\%$ (1), tagNode1

VGET,UY_node $\%$ nd $\%$ (1), tagNode2

$*$ ENDDO

!Write array in given format to file "Disp.inp"

*CFOPEN , C : UUsers \rbian \Desktop \ESLcomANSYS \5barras \Disp, inp

*VWRITE,UX_node1 (1) ,UY_node1 (1), UX_node2 (1) ,UY_node2 (1) ,UX_node3 (1) , . .

UY_node3 (1) ,UX_node4 (1),UY_node4 (1), UX_node5 (1), UY_node5 (1)

$(\mathrm{f} 10.6, \mathrm{f} 10.6, \mathrm{f} 10.6, \mathrm{f} 10.6, \mathrm{f} 10.6, \mathrm{f} 10.6, \mathrm{f} 10.6, \mathrm{f} 10.6, \mathrm{f} 10.6, \mathrm{f} 10.6)$

*CFCLOSE

*DO , e , 1 , NumElem, 1

tagElem $=13+\mathrm{e}$ 
ESOL , tagElem , e , , LS , 1

STORE, MERGE

*DIM, Sxx $\%$ \% , array, size

VGET , Sxx \% $\%$ (1), tagElem

$*$ ENDDO

!Write array in given format to file "Stresses.inp"

*CFOPEN , C : \Users \rbian \Desktop \ESLcomANSYS $\backslash 5$ barras $\backslash$ Stresses , inp

*VWRITE , $\operatorname{Sxx} 1(1), \operatorname{Sxx} 2(1), \operatorname{Sxx} 3(1), \operatorname{Sxx} 4(1), \operatorname{Sxx} 5(1)$

(f9.1,3X f f9.1, 3X,f9.1,f9.1, 3X,f9.1, 3X,f9.1, 3X ,f9.1, 3X , f9.1, 3X)

*CFCLOSE 